Prepared for the U.S. Department of Energy

under Contract DE-AC05-76RL01830

\title{
Frequency Response Analysis Tool
}

\author{
PV Etingov \\ D Kosterev \\ T Dai
}

December 2014

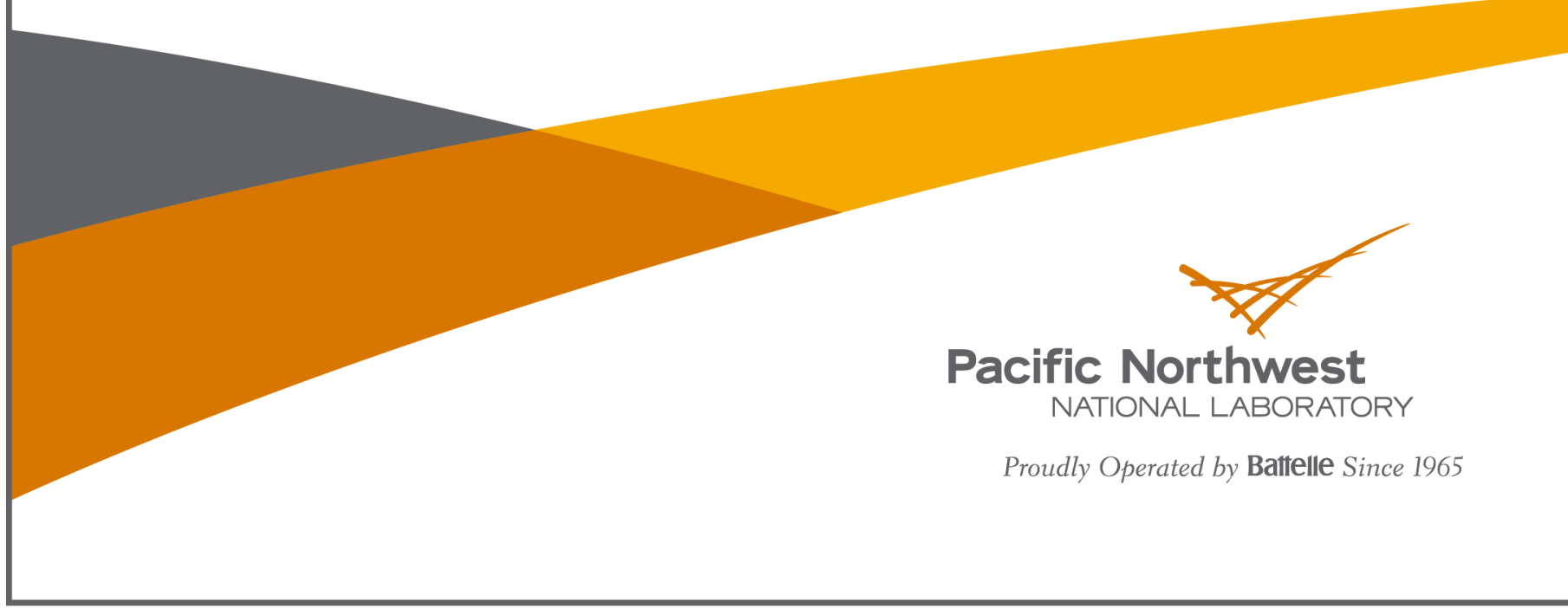




\title{
DISCLAIMER
}

This report was prepared as an account of work sponsored by an agency of the United States Government. Neither the United States Government nor any agency thereof, nor Battelle Memorial Institute, nor any of their employees, makes any warranty, express or implied, or assumes any legal liability or responsibility for the accuracy, completeness, or usefulness of any information, apparatus, product, or process disclosed, or represents that its use would not infringe privately owned rights. Reference herein to any specific commercial product, process, or service by trade name, trademark, manufacturer, or othenwise does not necessarily constitute or imply its endorsement, recommendation, or favoring by the United States Government or any agency thereof, or Battelle Memorial Institute. The views and opinions of authors expressed herein do not necessarily state or reflect those of the United States Government or any agency thereof.

\author{
PACIFIC NORTHWEST NATIONAL LABORATORY \\ operated by \\ BATTELLE \\ for the \\ UNITED STATES DEPARTMENT OF ENERGY \\ under Contract DE-AC05-76RLOI830
}

Printed in the Enited States of Ameriea

Available to DOE and DOE contractors from the

Office of Scientific and Technical Information.

P.O. Box 62, Oak Ridge, TN 37831-0062:

ph: (865) 576-8401

fax: $(865) 576.5728$

email: reportsa adonisosti.gov

Available to the public from the National Technical Information Service

5301 Shawnee Rd., Alexandria, VA 22312

ph: (800) 553-NTIS (6847)

cmail: ondersantic.eov 〈bttp:/www.ntis.gov/aboat/form_asps

Online ordering: http://www.ntis.gov 


\section{Frequency Response Analysis Tool}

PV Etingov, Senior Research Engineer

D Kosterev, Principal Engineer (Bonneville Power Administration) T Dai, Ph.D. Intern

December 2014

Prepared for the U.S. Department of Energy under Contract DE-AC05-76RL01830 


\begin{abstract}
Frequency response has received a lot of attention in recent years at the national level, which culminated in the development and approval of North American Electricity Reliability Corporation (NERC) BAL-003-1 Frequency Response and Frequency Bias Setting Reliability Standard.

This report is prepared to describe the details of the work conducted by Pacific Northwest National Laboratory (PNNL) in collaboration with the Bonneville Power Administration and Western Electricity Coordinating Council (WECC) Joint Synchronized Information Subcommittee (JSIS) to develop a frequency response analysis tool (FRAT). The document provides the details on the methodology and main features of the FRAT. The tool manages the database of under-frequency events and calculates the frequency response baseline. Frequency response calculations are consistent with frequency response measure (FRM) in NERC BAL-003-1 for an interconnection and balancing authority. The FRAT can use both phasor measurement unit (PMU) data, where available, and supervisory control and data acquisition (SCADA) data. The tool is also capable of automatically generating NERC Frequency Response Survey (FRS) forms required by BAL-003-1 Standard.
\end{abstract}

The tool has been released under an open source license. The primary users of the FRAT are balancing authorities and reliability coordinators. PNNL is continuously working on the FRAT development and improvement. Based on the industry feedback, new functions can be added. 



\section{Summary}

Electrical interconnection must be operated within a secure frequency range to maintain a continuous balance between the system demand, interchange, and generation. Interconnection frequency deviation could cause significant negative impacts on system reliability and control performance.

Federal Energy Regulatory Commission (FERC) states in [1]: "Frequency response (FR) is a measure of an Interconnection's ability to stabilize frequency immediately following the sudden loss of generation or load, and is a critical component of the reliable operation of the power system, particularly during disturbances and recoveries." Frequency response has received much attention in recent years at the national level, culminating in the development and approval of the North American Electricity Reliability Corporation (NERC) BAL-003-1 Frequency Response and Frequency Bias Setting Reliability Standard [2]. The Standard determines the amount of frequency response required in each interconnection and the allocation of frequency response obligation among balancing authorities.

This report is prepared to describe the details of the work conducted by Pacific Northwest National Laboratory (PNNL) in collaboration with Bonneville Power Administration and Western Electricity Coordinating Council (WECC) Joint Synchronized Information Subcommittee (JSIS) to develop a frequency response analysis tool (FRAT). The initial project was funded by the Office of Electricity Delivery and Energy Reliability (OE) at the U.S. Department of Energy (DOE) under the American Recovery and Reinvestment Act (ARRA) of 2009 and by the Bonneville Power Administration. The ongoing project is funded by the DOE OE through the Consortium for Electric Reliability Technology Solutions (CERTS) program.

The main goal of the tool is to automate the power system frequency response analysis process. The FRAT performs the estimation of the frequency response characteristics based on the phasor measurement unit (PMU) and supervisory control and data acquisition (SCADA) measurements, manages the database of under-frequency events and calculates the frequency response baseline. Frequency response calculations are consistent with frequency response measure (FRM) in NERC BAL-003-1 for an interconnection and balancing authority. The FRAT can use both PMU data, where available, and SCADA data. The tool is also capable to automatically generate NERC Frequency Response Survey FRS forms required by BAL-003-1 Standard. The primary users of the FRAT are balancing authorities and reliability coordinators.

The first version of the FRAT (version 1.0) was released under an open source license in 2013. PNNL is continuously working on the FRAT development and improvement. Based on the feedback received from the industry partners, the new fully redesigned version of the application (FRAT 2.0) has been developed and released under an open source license in August 2014.

The FRAT is a standalone Windows application with a user friendly graphical user interface (GUI) and advanced visualization (Figure 1). The FRAT has been developed using Microsoft Visual Studio 2012 and it is based on Windows Presentation Foundation (WPF) technology. The FRAT main features include:

1) Calculating system mean frequency based on user specified PMU measurements. 
2) Performing initial estimation of the system FR parameters (initial frequency, minimum frequency, settling point, etc.).

3) Visually inspect and adjust initial estimation of FR parameters.

4) Calculating FR performance characteristics according to NERC BAL-003-01 Standard (MW/0.1 $\mathrm{Hz}$ at point $\mathrm{B}$ ), as well as additional performance metrics: FRM at minimum frequency (point $\mathrm{C}$ ), $30 \mathrm{sec}, 60 \mathrm{sec}, 90 \mathrm{sec}$, etc.).

5) Archiving the historic events into an internal database and baselining the system performance.

6) Performing statistical analysis (linear regression, basic descriptive statistics)

7) Visualizing FR performance using different plots (depending on date, time, day of the week, wind/solar generation penetration).

8) All graphs produced by the tool can be copied into clipboard or into file (.jpg or .emf formats).

9) Automatically generating reports (including FRS 1 form) in Word format.

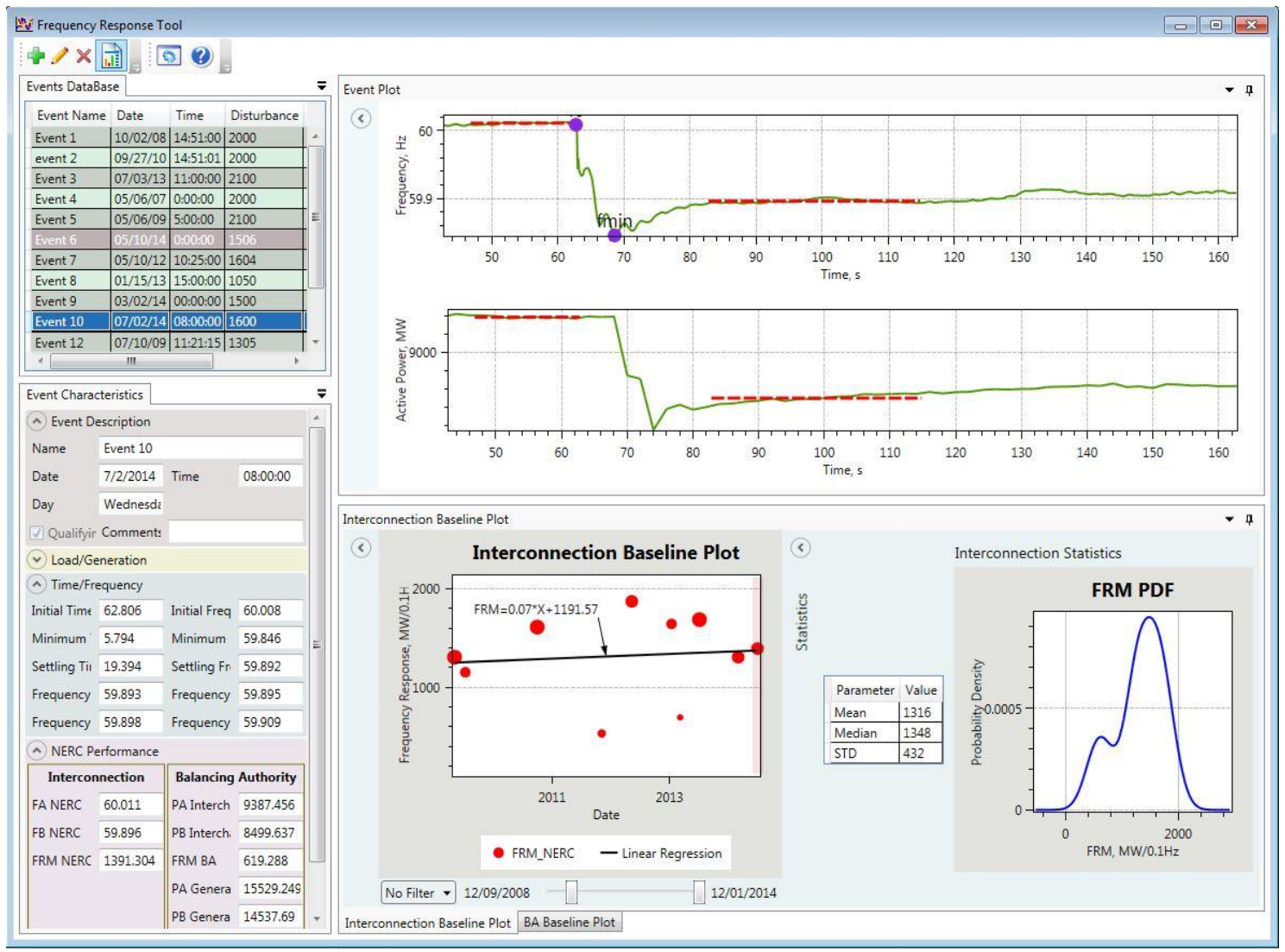

Figure 1. FRAT (version 2.0) GUI.

The developed PNNL FRAT application has been used by interconnections and balancing authorities (BAs) for a FR performance analysis and baselining. The FRAT application has been presented at industrial events including: 
- NERC Frequency Working Group

- NERC Resources Subcommittee

- Electricity Reliability Council of Texas (ERCOT) phasor measurement task force

- WECC JSIS

- WECC Modeling and Validation Work Group (MVWG)

- Webinars for Independent System Operator (ISO) New England and ERCOT.

The FRAT received very positive feedback from the users. Multiple entities expressed their interest to start testing and using the tool. The industrial users also provided valuable feedback for the continuing research. Based on the industry feedback, the major improvement of the tool should be extending the tool functionality to perform FR analysis for the individual generation units.

The FRAT future work will also involve the industry outreach including:

- Working closely with NERC (primarily with NERC Resources Subcommittee and Frequency Working Group) to promote nationwide dissemination of the tool among BAs and other electrical utilities.

- Working closely with NERC and the Consortium for Electric Reliability Technology Solutions (CERTS) to establish continuing support and maintenance of the FRAT.

- Working with BPA, ISO New England, ERCOT, WECC, and other BAs and utilities to provide them FR tool support and also to receive their feedback.

- Making presentations at North American Synchrophasor Initiative (NASPI), WECC JSIS, WECC MVWG, Institute of Electrical and Electronics Engineers (IEEE) and other industrial meetings and workshops.

The FRAT repository and online documentation can be found at: https://svn.pnl.gov/FRTool 



\section{Acknowledgments}

The initial project was funded by the Office of Electricity Delivery and Energy Reliability (OE),U.S. Department of Energy (DOE) under the American Recovery and Reinvestment Act (ARRA) of 2009 and by the Bonneville Power Administration. The ongoing project is funded by the DOE OE through the Consortium for Electric Reliability Technology Solutions (CERTS) program.

The project team is thankful for the support and valuable discussions on frequency response fundamentals to:

- Phillip Overholt, DOE OE

- Joe Eto, Lawrence Berkeley National Laboratory (LBNL), CERTS

- Bob Cummings, NERC

- Alison Silverstein, NASPI

- John Undrill

- Carlos Martinez, Advanced System Researchers (ASR)

- Sydney Niemeyer, NRG Energy

The project team appreciates contributions and support of the following PNNL engineers and managers:

- Jeffery Dagle, Chief Engineer, Team Lead

- David Chassin, Staff Scientist

- Yu Zhang, Senior Research Engineer

- Mark Morgan, Project Manager

- $\quad$ Eric Andersen, Project Manager

- Dale King, Product Line Manager

- Carl Imhoff, Electric Infrastructure Market Sector Manager

- Sue Arey, Project Specialist 



\section{Acronyms and Abbreviations}

BA

BPA

CERTS

DOE

ERO

FERC

FR

FRAT

FRM

FRO

FRS

FRSG

IFRO

JSIS

JOU

MW

NASPI

NERC

OE

PDF

PNNL

PMU

SCADA

UFLS

WECC
Balancing authority

Bonneville Power Administration

Consortium for Electric Reliability Technology Solutions

Department of Energy

Electric Reliability Organization

Federal Energy Regulatory Commission

Frequency response

Frequency response analysis tool

Frequency response measure

Frequency response obligation

Frequency Response Survey

Frequency Response Sharing Groups

Interconnection frequency response obligation

Joint Synchronized Information Subcommittee

Jointly owned unit

Megawatt

North American Synchrophasor Initiative

North American Electric Reliability Corporation

DOE Office of Electricity Delivery and Energy Reliability

Probability density function

Pacific Northwest National Laboratory

Phasor measurement unit

Supervisory control and data acquisition

Under-frequency load shedding

Western Electricity Coordinating Council 



\section{Contents}

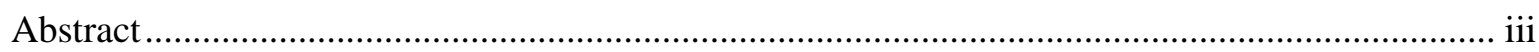

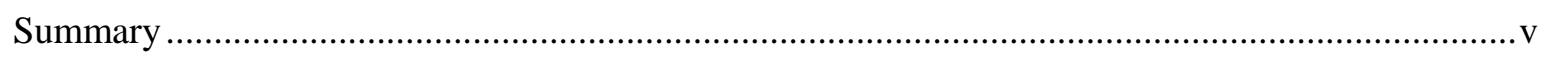

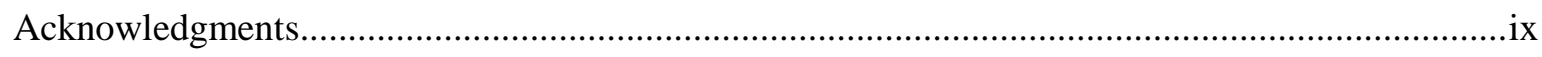

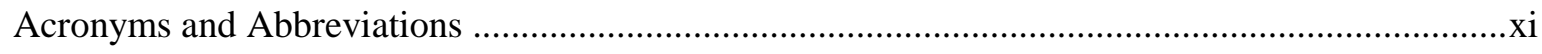

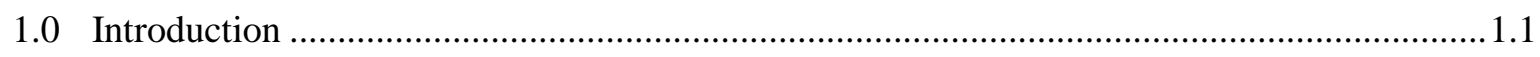

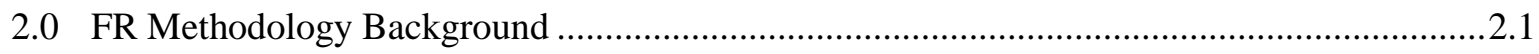

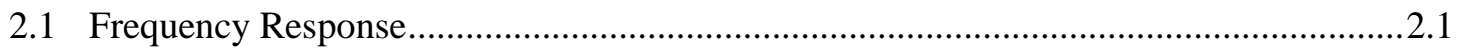

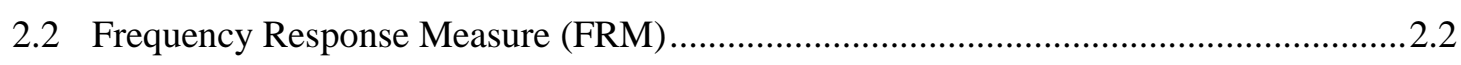

2.3 Interconnection Frequency Response Obligation (IFRO) ........................................... 2.4

2.4 Balancing Authority Frequency Response Obligation (FRO) .....................................2.4

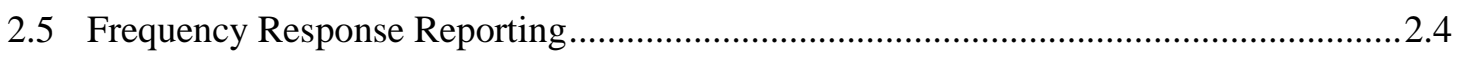

3.0 Frequency Response Analysis Tool Description ............................................................. 3.1

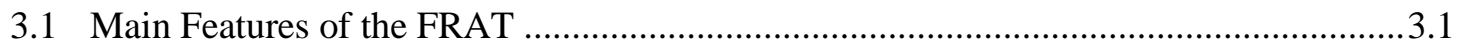

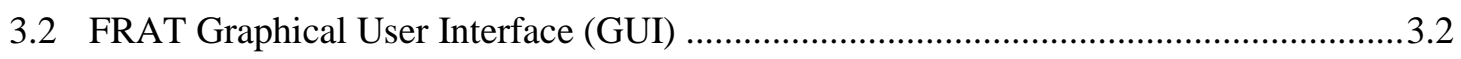

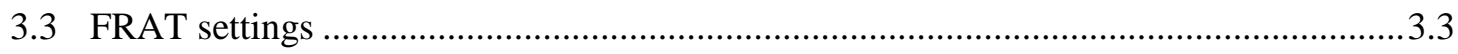

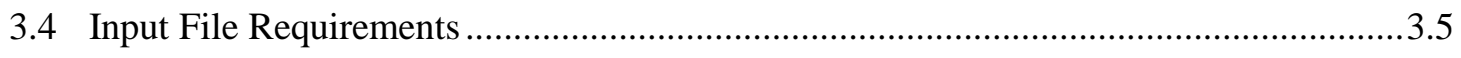

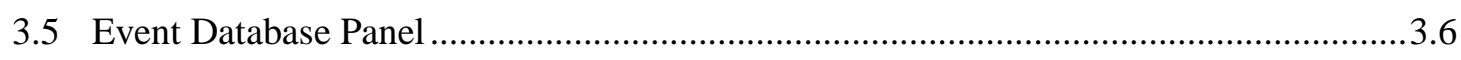

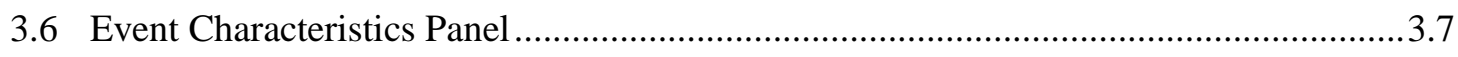

3.6.1 Event Description Group............................................................................. 3.8

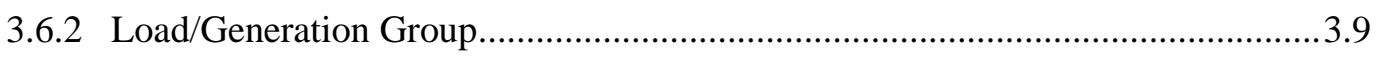

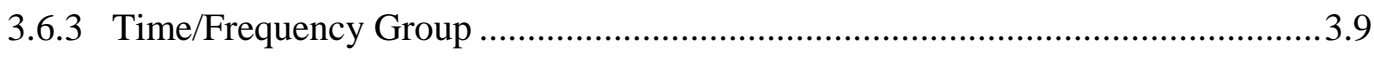

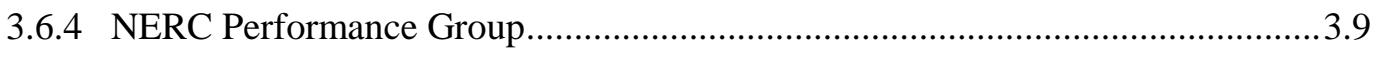

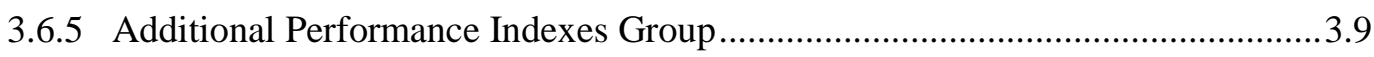

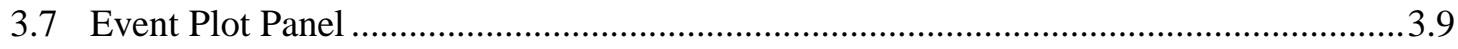

3.8 FRM Baseline and Statistical Analysis Screen ........................................................ 3.11

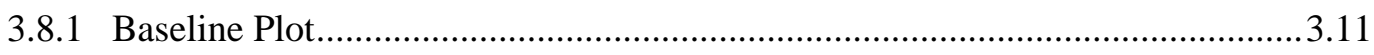

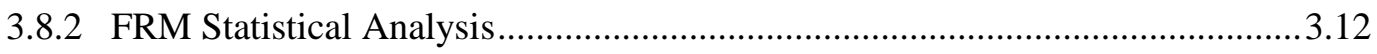

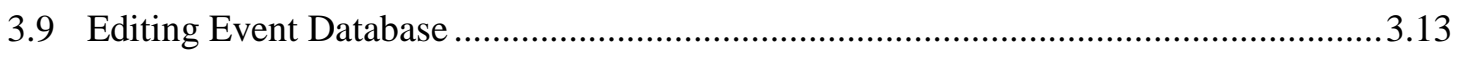

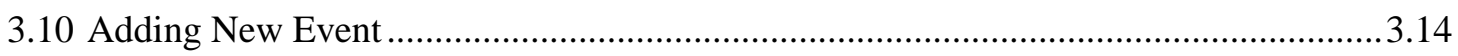

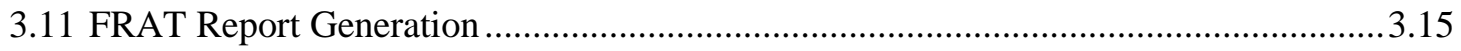

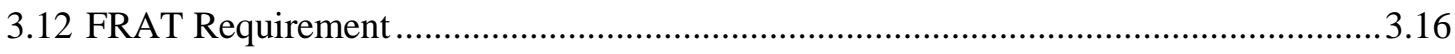

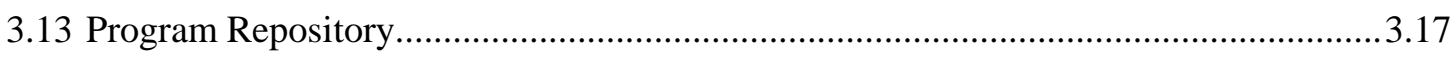

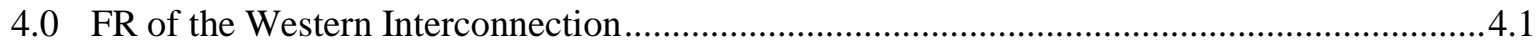

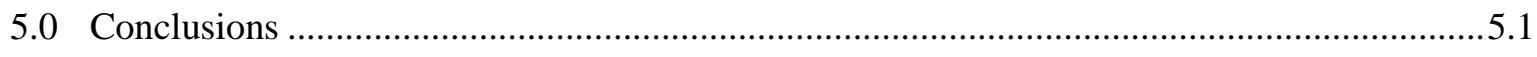

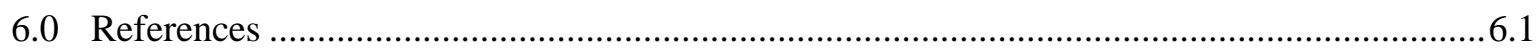




\section{Figures}

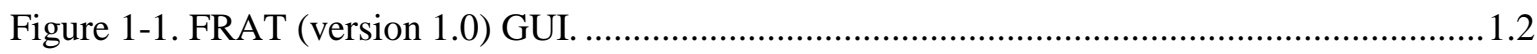

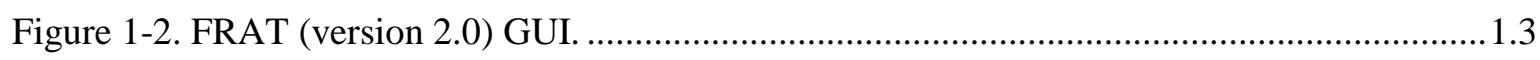

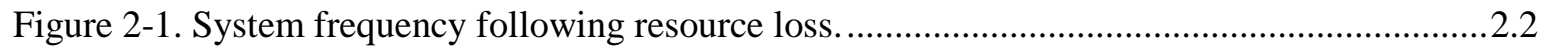

Figure 2-2. An example of the frequency event: a) interconnection frequency based on PMU measurements; b) actual net interchange based on SCADA measurements...........................2.3

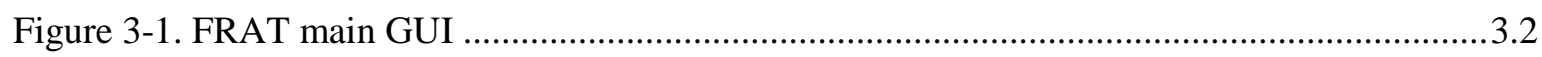

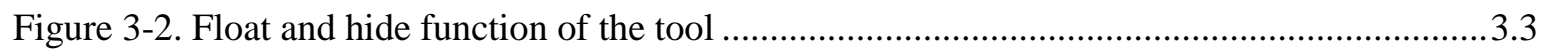

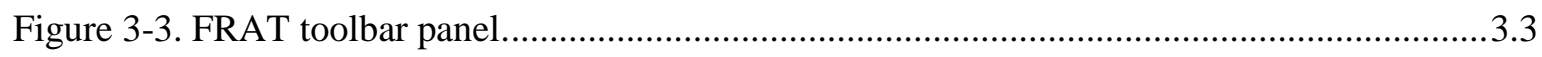

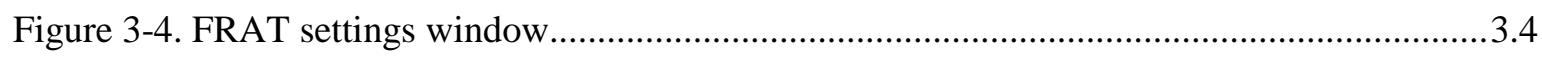

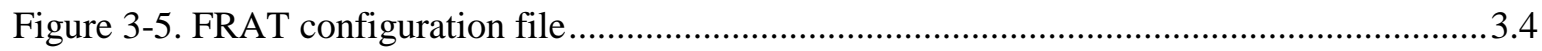

Figure 3-6. One row .csv file example: a) opened in text editor; b) opened in Excel......................3.5

Figure 3-7. Four rows .csv file example: a) opened in text editor; b) opened in Excel. ................... 3.6

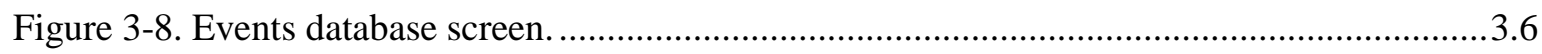

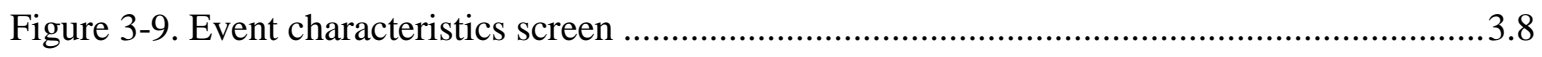

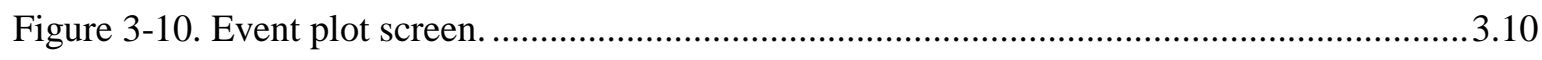

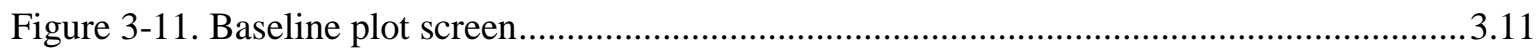

Figure 3-12. Baseline plot range selector.............................................................................. 3.12

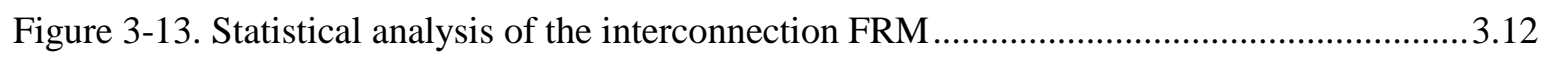

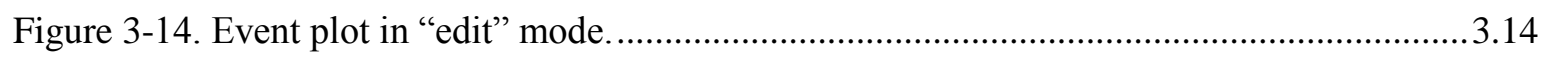

Figure 3-15. Frequency response analysis report screen .......................................................16

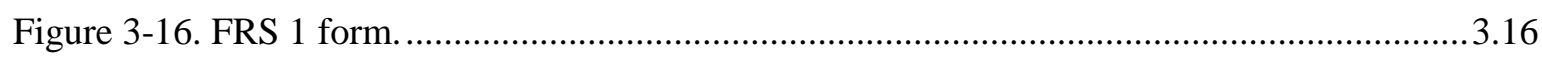

Figure 3-17. FRAT repository (main Wiki page) ................................................................... 3.17

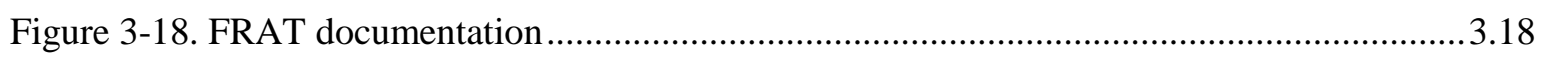

Figure 4-1. Frequency response baseline for Western Interconnection. ...................................... 4.1

Figure 4-2. Relationship between event size and historic frequency response measure................. 4.2

Figure 4-3. Ratio between frequency deviations at nadir (C) and settling (B) points.................... 4.2 


\section{Tables}

Table 2-1. Interconnection Frequency Response Obligations ...................................................2.4

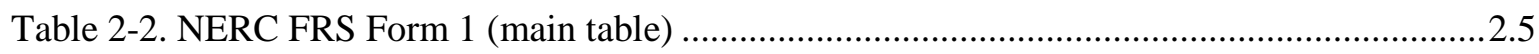

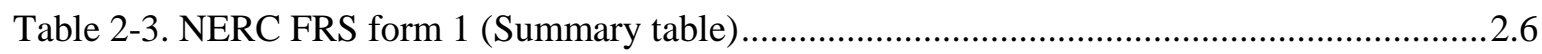

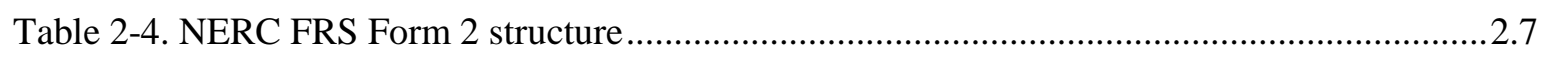

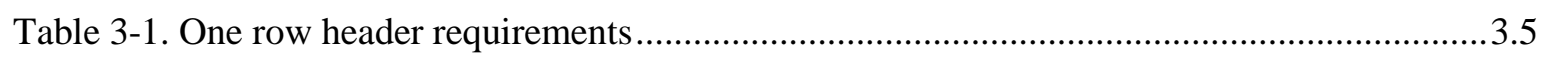

Table 3-2. Event characteristics columns definition ................................................................. 


\subsection{Introduction}

Electrical interconnection must be operated within a secure frequency range to maintain a continuous balance between the system demand, interchange, and generation. Interconnection frequency deviation could cause significant negative impacts on system reliability and control performance.

Federal Energy Regulatory Commission (FERC) states in [1]: "Frequency response is a measure of an Interconnection's ability to stabilize frequency immediately following the sudden loss of generation or load, and is a critical component of the reliable operation of the power system, particularly during disturbances and recoveries." Frequency response has received much attention in recent years at the national level, culminating in the development and approval of the North American Electric Reliability Corporation (NERC) BAL-003-1 Frequency Response and Frequency Bias Setting Reliability Standard [2]. The Standard determines the amount of frequency response required in each interconnection and the allocation of frequency response obligation among balancing authorities. The Standard is largely based on technical work done in the NERC Frequency Response Initiative [3] and Lawrence Berkeley National Laboratory (LBNL)-led work on frequency response metrics [4].

The Western Electricity Coordinating Council (WECC) has a long history of frequency response monitoring. WECC made several attempts to develop its own regional frequency responsive reserve (FRR) Standard or criteria [5], well before the NERC Standard. WECC's objectives were to: (a) ensure that an adequate amount and quality of frequency responsive reserves are carried in the interconnection, and (b) achieve even distribution of frequency response across the interconnection to mitigate the frequency response impacts on transmission paths. WECC has used synchrophasor data to monitor frequency response in the Western Interconnection.

Bonneville Power Administration (BPA) implemented the practice of using synchrophasor data for governor response validation [6]. These efforts greatly improved the accuracy of frequency response representation in power system studies, as evident from a number of system-wide validation studies.

PNNL in collaboration with BPA and Western Electricity Coordinating Council (WECC) Joint Synchronized Information Subcommittee (JSIS) developed a tool to automate the analysis of interconnections frequency response [7]. The tool can help to perform the estimation of the frequency response characteristics based on the phasor measurement unit (PMU) and supervisory control and data acquisition (SCADA) measurements, and collect and process statistical information on the frequency response characteristics. The tool can also represent the information using advanced visualization techniques.

The first version of the FRAT (Version 1.0) was released under open source license in 2013. A screenshot of the FRAT 1.0 GUI is shown in Figure 1-1.

The FRAT 1.0 has the following main features:

- Automation of frequency response analysis process;

- Calculation of the interconnection frequency response measure (FRM) using PMU and SCADA data; 
- Initial estimation of the FR parameters (initial frequency, minimum frequency, settling point, etc.)

- Visual inspection and manual adjustment of system parameters

- Archiving the historic events and baselines the interconnection performance;

- Automatically generating reports in MS Word format;

- User friendly graphical user interface (GUI)

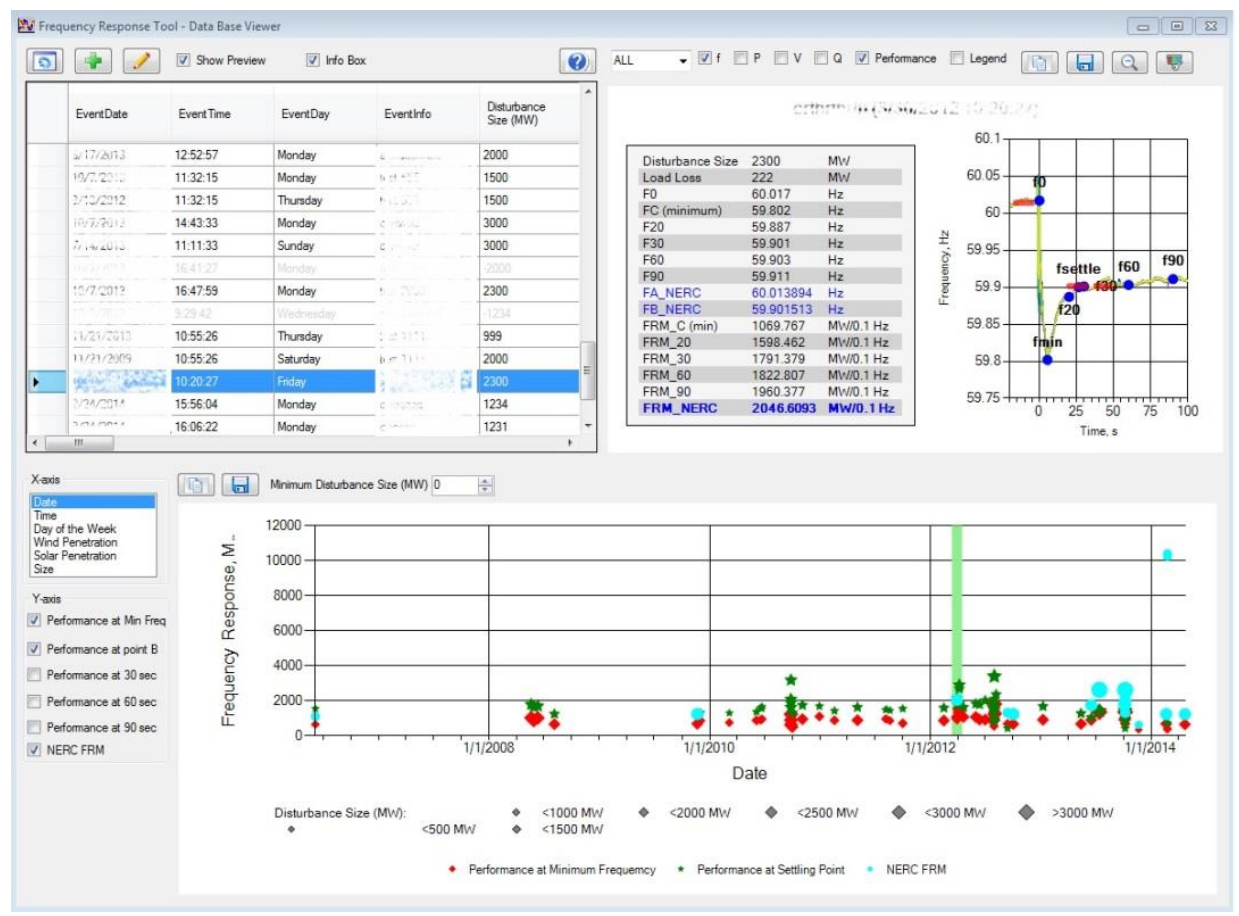

Figure 1-1. FRAT (version 1.0) GUI.

Based on the feedback received from the industry partners, the new version of the tool (FRAT 2.0) has been developed and released under an open source license in August 2014. The tool GUI is shown in Figure 1-2. The new version of the tool includes all features from the previous version as well as new functionality requested by the users and improved GUI.

The new FRAT features include:

- New analytical functions including:

- calculation of the interconnection and balancing authority frequency response measure (FRM) according to the NERC BAL-003-01 Standard;

- statistical analysis;

- New completely redesigned user interface;

- New advanced visualization;

- New reporting capabilities;

- Support of different data sources. 
The report presents details on the frequency response analysis, brief description of the NERC BAL003-01 Standard and description of the FRAT tool.

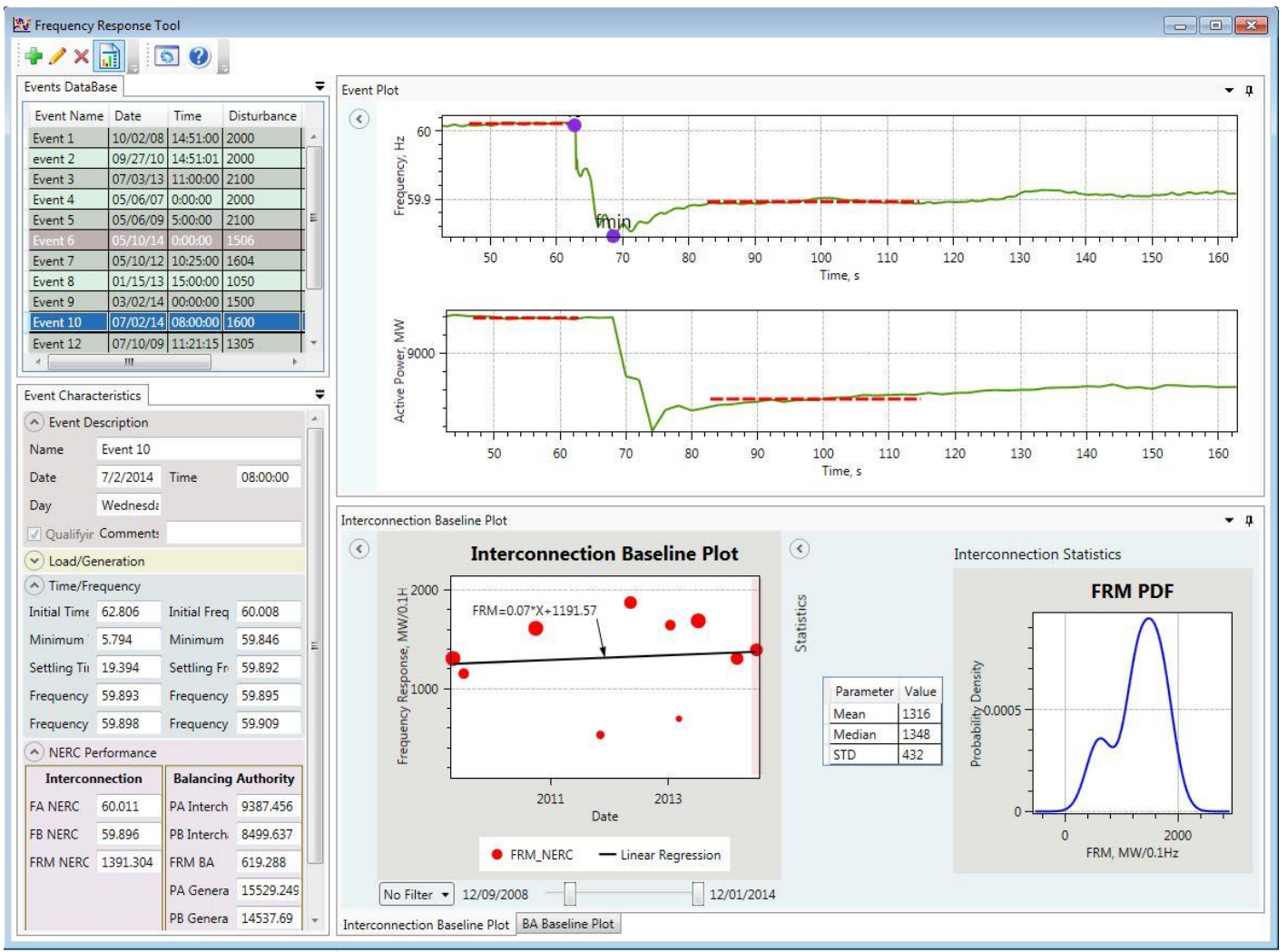

Figure 1-2. FRAT (version 2.0) GUI. 


\subsection{FR Methodology Background}

Frequency control comes from three major components. Control actions provided by these components have different response time and time windows [2].

Primary frequency control (or frequency response) is an action provided by interconnections to restore the system frequency in response to frequency deviation. Frequency response is provided by the synchronous generators equipped with the speed governor and also by some loads (typically motors).

Secondary frequency control is an action provided by a BA to supervise the primary controls to manage the allocation of load among the power plants. Secondary frequency control actions come from an automated dispatch system (automatic generation control (AGC)) or from manual operator dispatch commands.

Tertiary frequency control action is provided by a balancing authority (BA), and it involves centrally coordinated actions to dispatch (move) generation to a new operating point to maintain balance between generation and load. Tertiary frequency control is the slowest action, and it is also known as an "economic dispatch" or "load following".

\subsection{Frequency Response}

The NERC defines frequency response as [2]:

- "(Equipment) The immediate and automatic reaction or response of power from a system or power from elements of the system to a change in locally sensed system frequency.

- (System) The sum of the change in demand, and the change in generation, divided by the change in frequency, expressed in megawatts per $0.1 \mathrm{Hertz}(\mathrm{MW} / 0.1 \mathrm{~Hz})$ ".

As the definition stated, frequency response reacts to the change in frequency in the system. It is the first line of defense against involuntary power interruptions, which can occur within a few seconds of system disturbance. Different resources, loads and systems can automatically provide frequency response with different response time based on the current system conditions.

Figure 2-1 shows a typical frequency recording following a resource loss in the interconnection. Point $\mathrm{A}$ is frequency prior to a resource loss, calculated as an average frequency over 16 seconds prior to an event. Point $\mathrm{B}$ is the settling frequency, calculated as an average frequency from 20 to 52 seconds following a resource loss. Point $\mathrm{C}$ is the minimum (nadir) frequency. NERC frequency response measure (FRM) is calculated at point B. Eto et al. [4] considered nadir-based frequency response measurement at point $\mathrm{C}$.

Nadir-based frequency response is a better measure of the primary frequency response. WECC uses PMU measurements to calculate both the nadir and Point B frequency responses. However, the nadir response measurement at BA level requires synchronized high resolution PMU measurements of BA frequency and interchange power flows. Most BAs in the NERC footprint use 4-second non-synchronized 
data, making the nadir frequency response measurement unfeasible. Therefore, frequency response at Point B is used as a practical alternative in NERC BAL-003-1 reliability Standard.

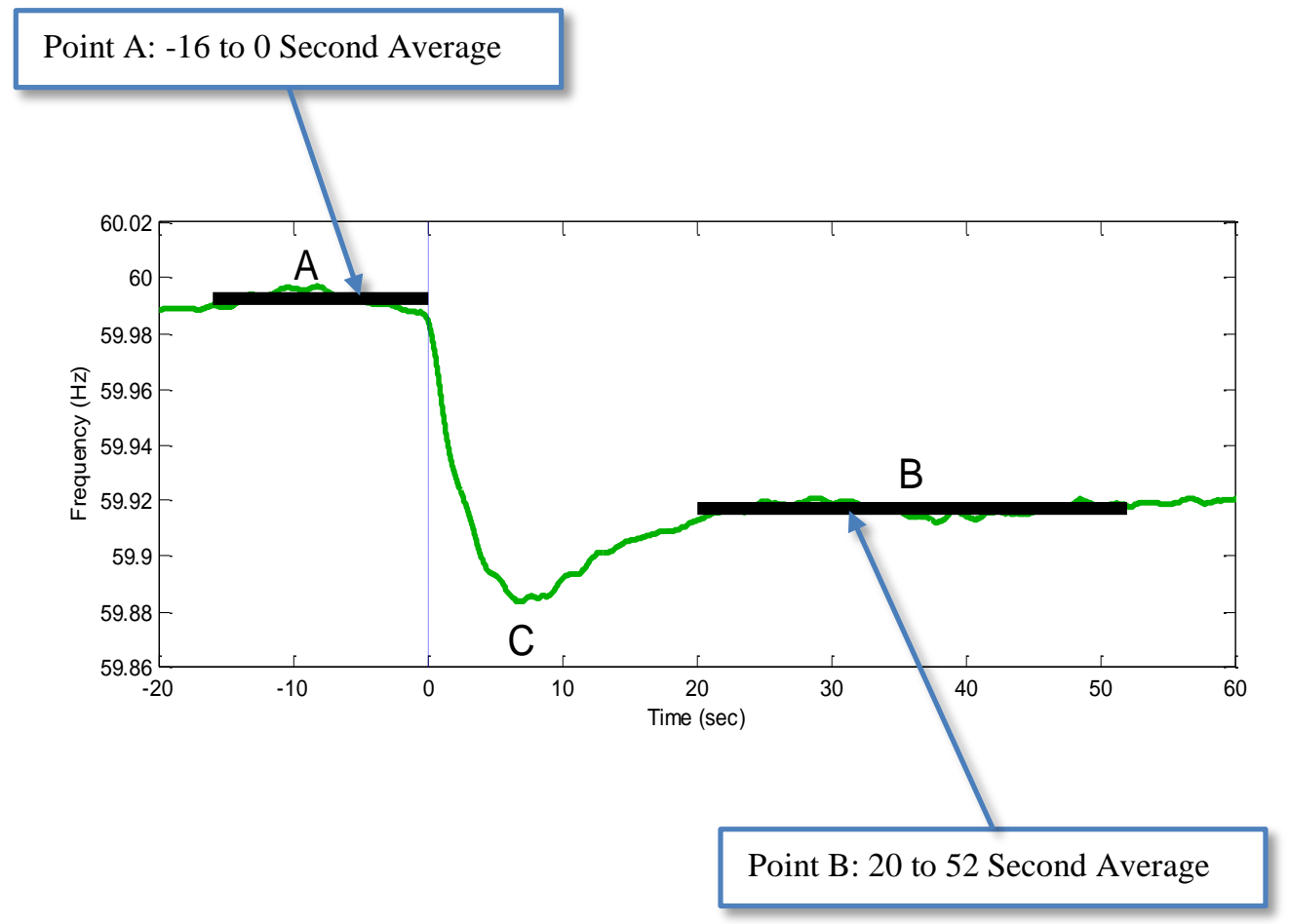

Figure 2-1. System frequency following resource loss.

\subsection{Frequency Response Measure (FRM)}

The FRM can be computed from the single event frequency response data (SEFRD), defined as "the data from an individual event from a BA that is used to calculate its FR, expressed in MW/0.1Hz" [2].

The BA FRM for a single event can be calculated using the following formula:

$$
F R M_{B A}=\left(\left(P_{I N T_{-} B}-A d j_{B}\right)-\left(P_{I N T_{-} A}-A d j_{A}\right)\right) / 10\left(f_{B}-f_{A}\right),
$$

where $P_{I N T_{-} B}$ is a value of interchange power flow at point B;

$P_{I N T_{-} A}$ is a value of interchange power flow at point A;

$A d j_{B}$ is a point B value adjustment;

$A d j_{A}$ is a point A value adjustment;

$f_{A}$ is a value of interconnection frequency at point $\mathrm{A}$;

$f_{B}$ is a value of interconnection frequency at point $\mathrm{B}$;

As seen from Equation (2.1), BA FRM calculation requires interchange measurements.

Unfortunately very few interchange points have PMUs, so the BA frequency response calculations use SCADA data. SCADA measurements are not time-synchronized and the result of such skew is seen in Figure 2-2. SCADA data also lags PMU measurements by several seconds. Thus, at present, those BAs that are using SCADA data for frequency response monitoring are likely to be reporting response values 
that are not precisely synchronized with interconnection-wide frequency response values measured using PMUs. It will be highly desirable to have PMUs or relay-enabled PMUs at all tie-lines for measurement synchronization, to obtain better quality frequency measurements.

a)

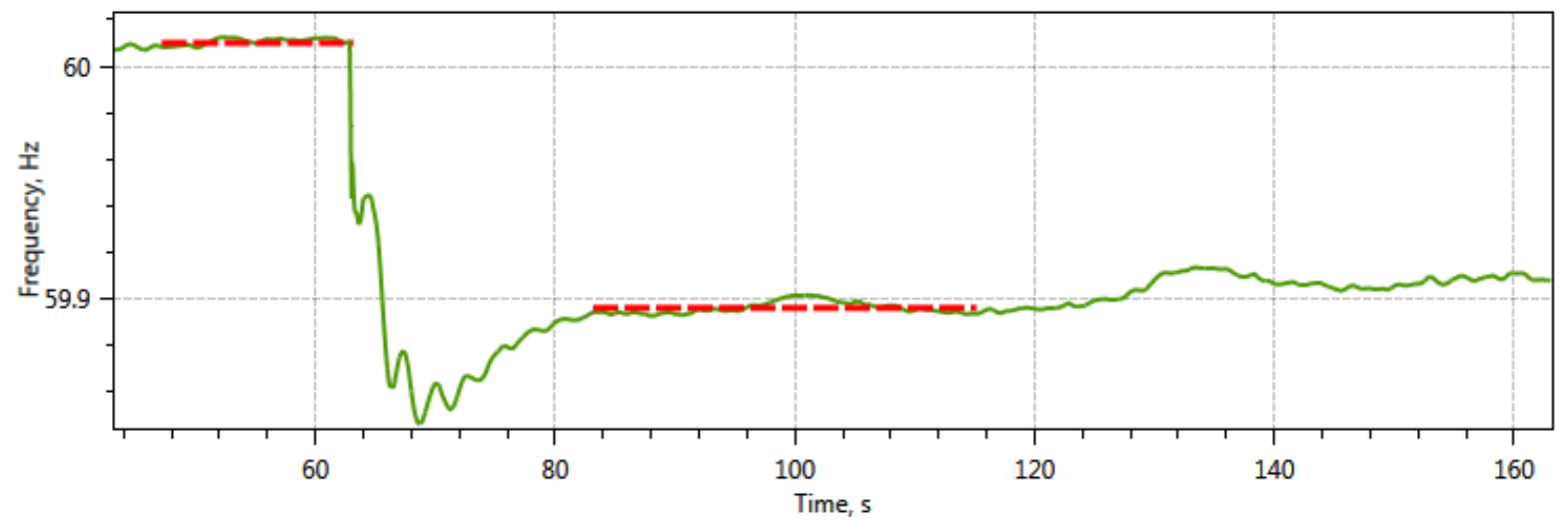

b)

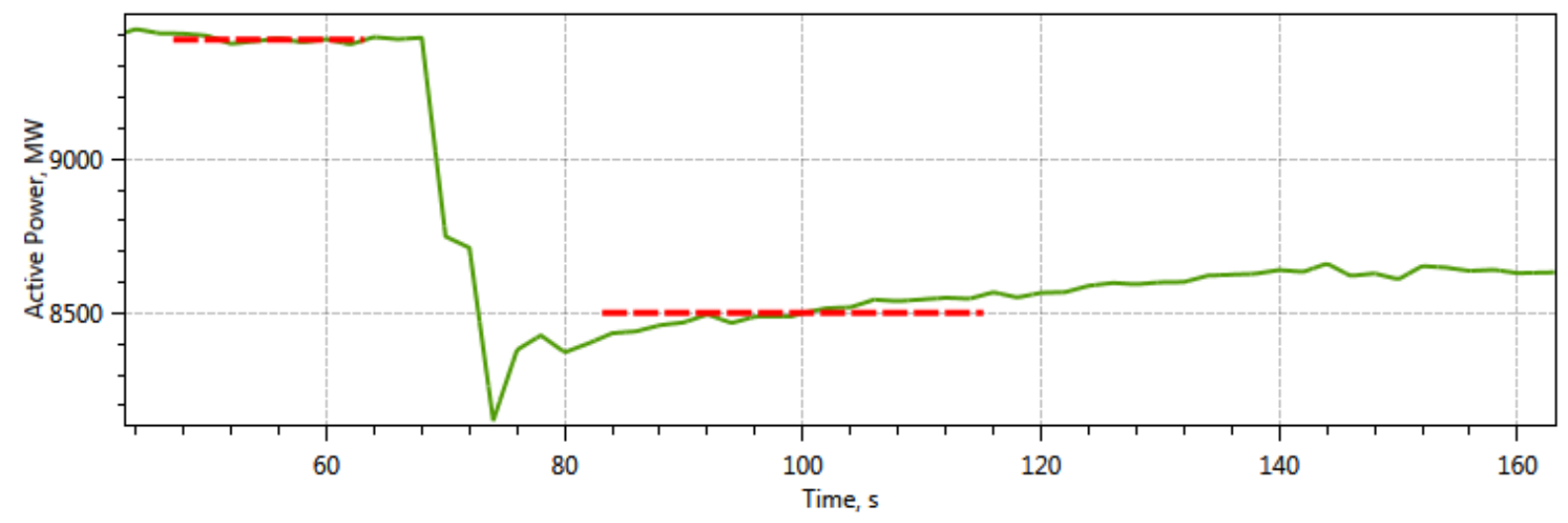

Figure 2-2. An example of the frequency event: a) interconnection frequency based on PMU measurements; b) actual net interchange based on SCADA measurements.

Adjustment of points A and B values according to BAL-003-01 Standard could include the following components [2]:

- Jointly owned units (JOU) dynamic schedule adjustment

- Non-conforming load adjustment (load outside of normal load profile)

- $\quad$ Pumped-hydro generation adjustment

- Transferred frequency response

- Contingent BA adjustment.

The interconnection FRM for a single event is calculated as following:

$$
F R M_{\text {Interconnection }}=\left(P_{\text {GenLoss }}-P_{\text {LoadLoss }}\right) / 10\left(f_{B}-f_{A}\right),
$$


where $P_{\text {GenLoss }}$ is an interconnection generation loss;

$P_{\text {LoadLoss }}$ is an interconnection load loss.

\subsection{Interconnection Frequency Response Obligation (IFRO)}

The Electric Reliability Organization (ERO) has established a targeted contingency protection criterion for each interconnection called interconnection frequency response obligation (IFRO). An IFRO is calculated as the amount of power lost in the contingency event divided by the maximum frequency change in the event $(\mathrm{MW} / 0.1 \mathrm{~Hz})$. For example, for the WECC system the design N-2 event is Palo Verde outage, and it should not result in under-frequency load shedding (UFLS) which is starting at $59.5 \mathrm{~Hz}$ in the Western Interconnection. The calculated values of IFRO for all three major interconnections in the U.S. are given in Table 2-1 [2].

Table 2-1. Interconnection Frequency Response Obligations

\begin{tabular}{|l|l|}
\hline Interconnection & IFRO, MW/0.1Hz \\
\hline Western (WECC) & -840 \\
\hline Eastern & -1002 \\
\hline ERCOT (Texas) & -286 \\
\hline
\end{tabular}

\subsection{Balancing Authority Frequency Response Obligation (FRO)}

Each BA within an interconnection has the obligation to provide its share of the total IFRO. The equation to calculate FRO for each BA is as follows:

$$
F R O_{B A}=I F R O * \frac{\text { Annual Gen }_{B A}+\text { Annual Load }_{B A}}{\text { Annual Gen }_{\text {Int }}+\text { Annual Load }_{\text {Int }}}
$$

where Annual Gen $_{B A}$ is the annual BA generation;

Annual $\operatorname{Load}_{B A}$ is the annual BA load;

Annual Gen $_{\text {Int }}$ is the annual interconnection generation;

Annual Load Int $_{\text {is }}$ the annual interconnection load.

\subsection{Frequency Response Reporting}

According to BAL-003-01 Standard, the median of all the FRM observations must be reported annually by BA or Frequency Response Sharing Groups (FRSG) to the ERO. In statistical theory, the median is the numerical value separating the higher half of a data sample from the lower half. The reason why the median value is used is that the median value gives a better representation of central tendency than average value. The average can be significantly influenced by the few values, making it not very representative of the majority of the values in the data set. 
Each BA or FRSG should achieve an annual FRM equal to or less than its FRO to ensure that sufficient frequency response is provided to maintain interconnection frequency response that should equal to or less than the IFRO [2] ${ }^{1}$.

Each BA or FRSG should submit the FRS forms 1 and 2 to the ERO. FRS form 1 contains information on all frequency events. There is only one exception when an event can be excluded from the annual FRS form 1 submission -- if the interchange or frequency data is corrupt or energy management system (EMS) was unavailable. The FRS 1 main form structure is given in Table 2-3 and a summary table is given in Table 2-3.

FRS form 2 is created for each frequency event separately. Information from the FRS 2 forms is used as an input to create the FRS form 1. The FRS form 2 structure is given in Table 2-4.

Table 2-2. NERC FRS Form 1 (main table)

\begin{tabular}{|c|c|c|}
\hline \# & Column & Description \\
\hline 1 & Event number & \\
\hline 2 & UTC date/time & \\
\hline 3 & Prevailing data/time & Time used by interconnection \\
\hline 4 & $\begin{array}{l}\text { Interconnection time } \\
\text { zone }\end{array}$ & \\
\hline 5 & BA date/time & \\
\hline 6 & BA time zone & \\
\hline 7 & Delta frequency & $\mathrm{F}_{\mathrm{B}}-\mathrm{F}_{\mathrm{A}}$ \\
\hline 8 & BA time & Point A time \\
\hline 9 & $\begin{array}{l}\text { BA bias delta } \\
\text { frequency }\end{array}$ & $\mathrm{F}_{\mathrm{B}}-\mathrm{F}_{\mathrm{A}}$ \\
\hline 10 & $\begin{array}{l}\text { Relay limit delta } \\
\text { frequency }\end{array}$ & Delta frequency in case of relay limit R1 violation \\
\hline 11 & Value A NAI & Net interchange value at point $\mathrm{A}=P_{I N T \_A}$ \\
\hline 12 & Value $\mathrm{A}$ adjustment & Net interchange point $\mathrm{A}$ adjustment $=A d j_{A}$ \\
\hline 13 & Value B NAI & Net interchange value point $\mathrm{B}=P_{I N T_{-} B}$ \\
\hline 14 & Value B adjustment & Net interchange point $\mathrm{B}$ adjustment $=A d j_{B}$ \\
\hline 15 & FRM for bias & FRM calculated according to $(2.1)$ \\
\hline 16 & FRM for R1 & FRM in case of relay limit R1 violation \\
\hline 17 & Exclude for data error & yes/no \\
\hline
\end{tabular}

\footnotetext{
${ }^{1}$ FRO and IFRO values are negative. Therefor FRM should be less or equal than FRO.
} 
Table 2-3. NERC FRS form 1 (Summary table)

\begin{tabular}{|c|c|c|}
\hline \# & Column & Description \\
\hline 1 & Date & Event date \\
\hline 2 & A value time & Point A time \\
\hline 3 & $\mathrm{~F}$ point $\mathrm{A}, \mathrm{Hz}$ & Frequency at point $\mathrm{A}$ time \\
\hline 4 & A value, $\mathrm{Hz}$ & Point $\mathrm{A}$ frequency (average frequency at interval $\mathrm{T}_{0-16 \mathrm{sec}} \ldots \mathrm{T}_{0 \mathrm{sec}}$ ) \\
\hline 5 & t0 time & Initial point time \\
\hline 6 & $\mathrm{C}$ value, $\mathrm{Hz}$ & Point $\mathrm{C}$ frequency (minimum frequency value at interval $\mathrm{T}_{0} \ldots \mathrm{T}_{0+18 \mathrm{sec}}$ ) \\
\hline 7 & Frequency point $\mathrm{A}$ & Point $\mathrm{A}$ frequency (average frequency at interval $\mathrm{T}_{0-16 \mathrm{sec}} \ldots \mathrm{T}_{0 \mathrm{sec}}$ ) \\
\hline 8 & Net interchange, point $\mathrm{A}$ & Point $A$ interchange (average interchange at interval $T_{0-16 \text { sec }} \ldots T_{0 \mathrm{sec}}$ ) \\
\hline 9 & $\begin{array}{l}\text { JOU dynamic schedule, } \\
\text { Point A }\end{array}$ & JOU adjustment at point $\mathrm{A}$, Import(-)/Export(+) \\
\hline 10 & $\begin{array}{l}\text { Non-confirming load, } \\
\text { point A }\end{array}$ & Non-confirming load adjustment at point A, Load(-) \\
\hline 11 & Pump hydro, point $\mathrm{A}$ & Pump-hydro adjustment at point A, Load(-)/Gen(+) \\
\hline 12 & Not used & Future use \\
\hline 13 & Transferred FR, point A & Transferred FR adjustment at point $\mathrm{A}, \operatorname{Rec}(-) / \operatorname{Del}(+)$ \\
\hline 14 & Generation loss, point A & Contingent BA adjustment at point $\mathrm{A}$, load loss(-)/generation loss $(+)$ \\
\hline 15 & $\begin{array}{l}\text { BA frequency bias, point } \\
\text { A }\end{array}$ & BA frequency bias at point $\mathrm{A}$ \\
\hline 16 & BA load, point $\mathrm{A}$ & BA load at point $\mathrm{A}$ \\
\hline 17 & $\begin{array}{l}\text { BA EPFR bias settings, } \\
\text { point A }\end{array}$ & Expected primary frequency response at point $\mathrm{A}$ \\
\hline 18 & Frequency point B & Point B frequency (average frequency at interval $\mathrm{T}_{\mathrm{t} 0+20 \mathrm{sec}} \ldots \mathrm{T}_{\mathrm{t} 0+52 \mathrm{sec}}$ ) \\
\hline 19 & Net interchange, point B & Point $B$ interchange (average interchange at interval $T_{t 0+20 \mathrm{sec}} \ldots \mathrm{T}_{\mathrm{t} 0+20 \mathrm{sec}}$ ) \\
\hline 20 & $\begin{array}{l}\text { JOU dynamic schedule, } \\
\text { point B }\end{array}$ & JOU adjustment at point B, import(-)/export(+) \\
\hline 21 & $\begin{array}{l}\text { Non-confirming load, } \\
\text { point B }\end{array}$ & Non-confirming load adjustment at point B, load(-) \\
\hline 22 & Pump hydro, point B & Pump-hydro adjustment at point $\mathrm{B}, \operatorname{load}(-) / \mathrm{gen}(+)$ \\
\hline 23 & Not used & Future use \\
\hline 24 & Transferred FR, point B & Transferred FR adjustment at point $\mathrm{B}, \mathrm{rec}(-) / \mathrm{del}(+)$ \\
\hline 25 & Generation loss, point B & Contingent BA adjustment at point $\mathrm{B}$, load loss(-)/generation loss $(+)$ \\
\hline 26 & $\begin{array}{l}\text { Initial performance, } \\
\text { adjusted }\end{array}$ & In per unit (p.u.) \\
\hline 27 & $\begin{array}{l}\text { Initial performance, } \\
\text { unadjusted }\end{array}$ & In p.u. \\
\hline 28 & Sustained performance & In p.u. \\
\hline 29 & $\begin{array}{l}\text { BA frequency bias, point } \\
\text { B }\end{array}$ & BA frequency Bias at point $\mathrm{B}$ \\
\hline 30 & BA load, point B & BA load at point B \\
\hline 31 & $\begin{array}{l}\text { BA EPFR bias settings, } \\
\text { Point B }\end{array}$ & Expected primary frequency response at point B \\
\hline
\end{tabular}


Table 2-4. NERC FRS Form 2 structure

\begin{tabular}{|c|c|c|}
\hline$\#$ & Column & Description \\
\hline 1 & Time & $\begin{array}{l}\text { Timestamp, in case of SCADA data usage, the } 2 \text { seconds resolution is } \\
\text { normally used. }\end{array}$ \\
\hline 2 & Frequency & $\mathrm{Hz}$ \\
\hline 3 & $\begin{array}{l}\text { Net actual } \\
\text { interchange }\end{array}$ & MW \\
\hline 4 & $\begin{array}{l}\text { JOU dynamic } \\
\text { schedule }\end{array}$ & Import(-)/export(+) \\
\hline 5 & Non-conforming load & Load(-) \\
\hline 6 & Pumped hydro & $\operatorname{Load}(-) / \operatorname{Gen}(+)$ \\
\hline 7 & Not used & \\
\hline 8 & Transferred FR & $\operatorname{Rec}(-) / \operatorname{Del}(+)$ \\
\hline 9 & Contingent BA & Load Loss(-)/Generation Loss(+) \\
\hline 10 & BA bias & $\mathrm{MW} / 0.1 \mathrm{~Hz}$ \\
\hline 11 & BA load & MW \\
\hline
\end{tabular}




\subsection{Frequency Response Analysis Tool Description}

PNNL worked with BPA and WECC JSIS to develop a frequency response analysis tool (FRAT) to manage the database of under-frequency events and calculate the frequency response baseline. The application can use both PMU data, where available, and SCADA data. Frequency response calculations are consistent with frequency response measure (FRM) in NERC BAL-003-1 for an interconnection and balancing authority. In addition to NERC FRM, the application calculates the nadir frequency response. The frequency response metrics are saved in an extensive database. The primary users of the FRAT are balancing authorities and reliability coordinators.

\subsection{Main Features of the FRAT}

The purpose of the developed software tool is to automate the BA and interconnection frequency response analysis process. The tool performs the estimation of the frequency response characteristics according to the NERC BAL-003-01 Standard using SCADA and PMU measurements. The FRAT also can visualize FR information using different types of plots and perform statistical analysis. Reports (FRS forms) can be also automatically generated.

The FRAT is a standalone Windows application. It has a user friendly interface. The FRAT has been developed using Microsoft Visual Studio 2012. The FRAT features include:

- Calculating system mean frequency based on user-specified PMU measurements.

- Performing initial estimation of the system FR parameters (initial frequency, minimum frequency, settling point, etc.).

- Allow visual inspection and adjustment of initial estimation of FR parameters.

- Calculation of FR performance characteristics according to NERC BAL-003-01 Standard (MW/0.1 Hz at point B), as well as additional performance metrics: FRM at minimum frequency (point C), $30 \mathrm{sec}, 60 \mathrm{sec}, 90 \mathrm{sec}$, etc.).

- Archiving the historic events into internal database and baselining the system performance.

- Performing statistical analysis (linear regression, basic descriptive statistics)

- Visualizing FR performance using different plots (depending on date, time, day of the week, wind/solar generation penetration).

- Allow all graphs produced by the tool to be copied into clipboard or into file (.jpg or .emf formats).

- Automatically generating reports (including FRS 1 form) in Word format. 


\subsection{FRAT Graphical User Interface (GUI)}

Figure 3-1 shows an interactive display of the frequency response analysis tool (Version 2.0). The GUI consists from the toolbar and four major panels (screens):

1) Event database screen - to show the list of frequency events and basic information about these events.

2) Event details and system performance screen - to show the event details (initial frequency, settling frequency, minimum frequency, etc.), interconnection/BA information (generation, load, generation by type of units, etc.), FR characteristics (BA FRM, interconnection FRM, etc.)

3) Event plot - to graphically display the event. This screen consists from three subplots for frequency, active power and voltage.

4) FRM baseline and analysis screen - to show the FR performance baseline and statistical analysis of the events.

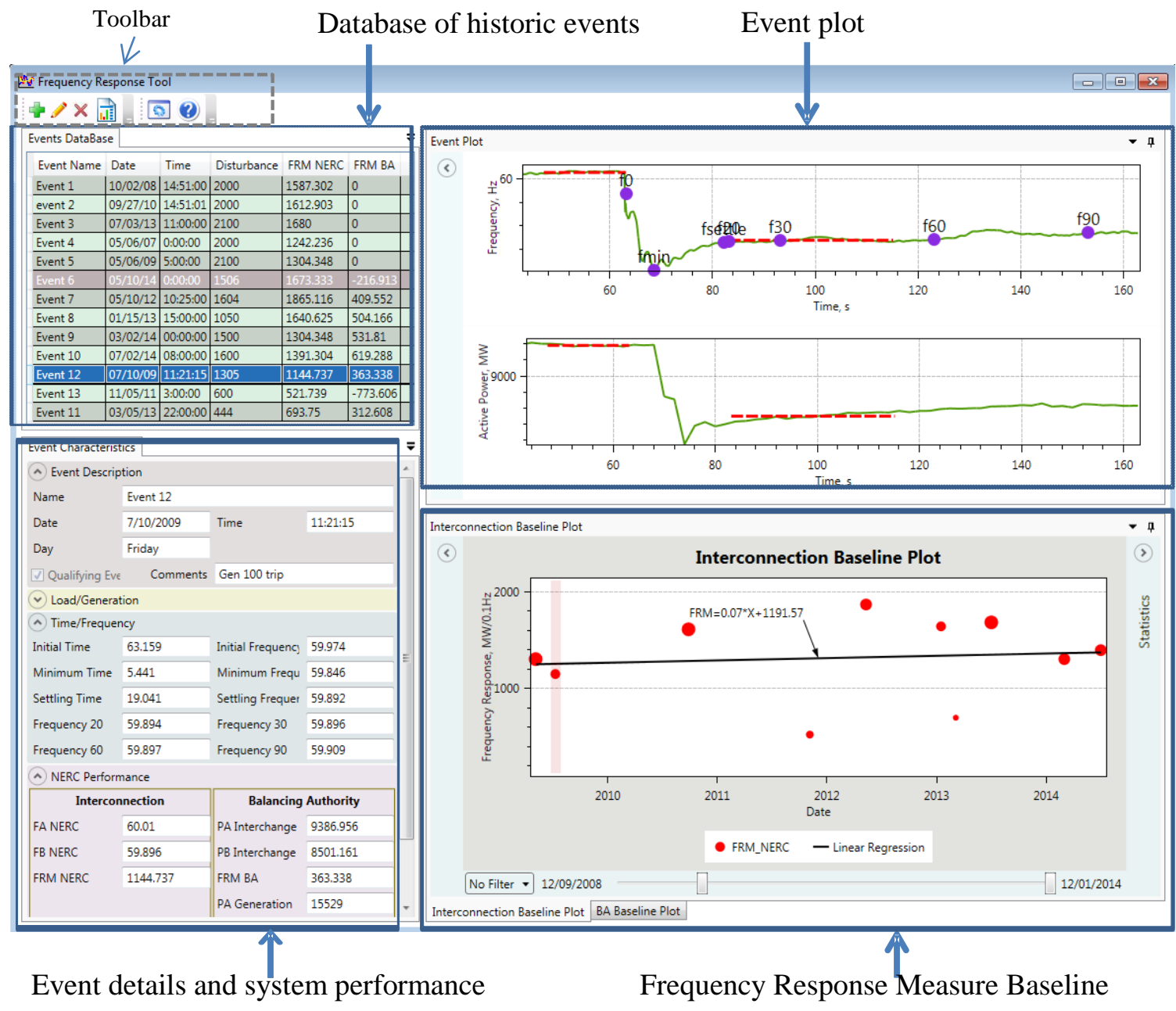

Figure 3-1. FRAT main GUI 
All of these screens can float and be rearranged by the user. Also these screens can be hidden if not needed. Figure 3-2 shows how to close or hide the panel.

\begin{tabular}{|c|c|c|c|c|c|c|}
\hline & & & \multicolumn{2}{|c|}{ Float the screen } & \multicolumn{2}{|r|}{ Hide the screen } \\
\hline \multicolumn{7}{|c|}{ Events DataBase } \\
\hline Event Name & Date & Time & Disturbance & FRM NERC & FRM BA & \\
\hline Event 1 & $10 / 02 / 08$ & 14:51:00 & 2000 & $\mid 1515.152$ & 0 & \\
\hline Event 2 & $09 / 27 / 10$ & 14:51:01 & 2000 & 1612.903 & 0 & \\
\hline Event 3 & 07/03/13 & 11:00:00 & 2100 & 1680 & 0 & \\
\hline Event 4 & 05/06/07 & 0:00:00 & 2000 & 1242.236 & 0 & \\
\hline Event 5 & $05 / 06 / 09$ & 5:00:00 & 2100 & 1304.348 & 0 & \\
\hline
\end{tabular}

Figure 3-2. Float and hide function of the tool

The FRAT toolbar consists from several buttons to add/edit/delete events, to specify the program settings, and get the program help (Figure 3-3).

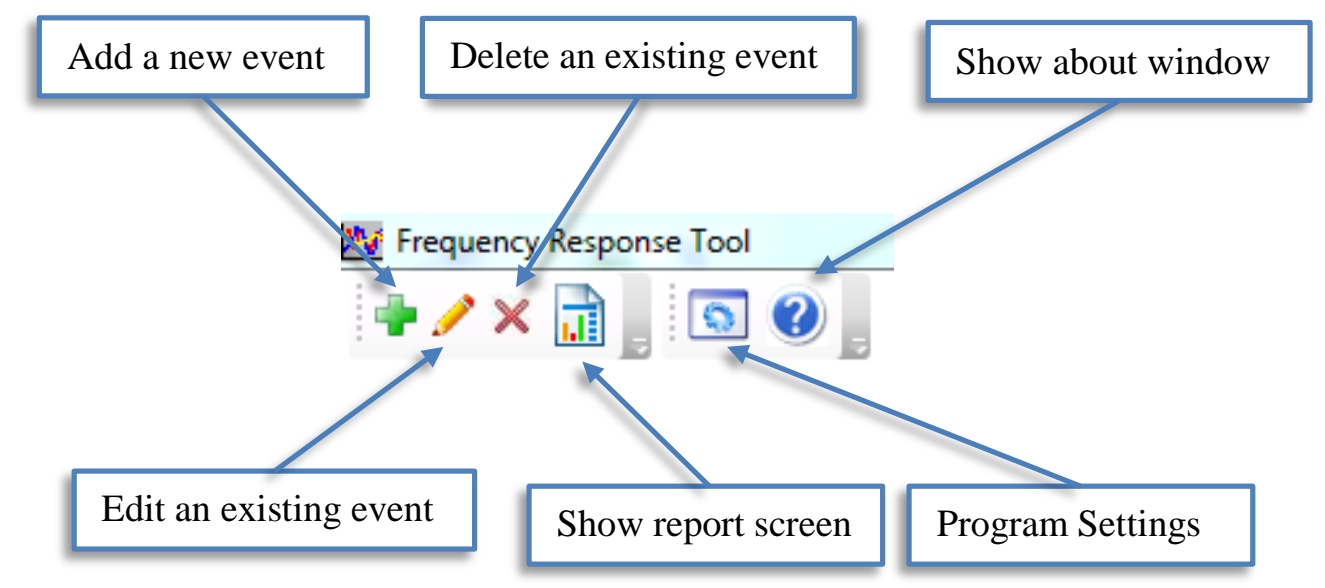

Figure 3-3. FRAT toolbar panel.

\subsection{FRAT settings}

The settings button $\square$ is used to open the settings window (Figure 3-4). In the settings window, the BA information (BA name, BA time zone and interconnection prevailing time zone) and input signals name (columns header) for net interchange, total generation, wind generation, hydro generation and thermal generation can be specified. 


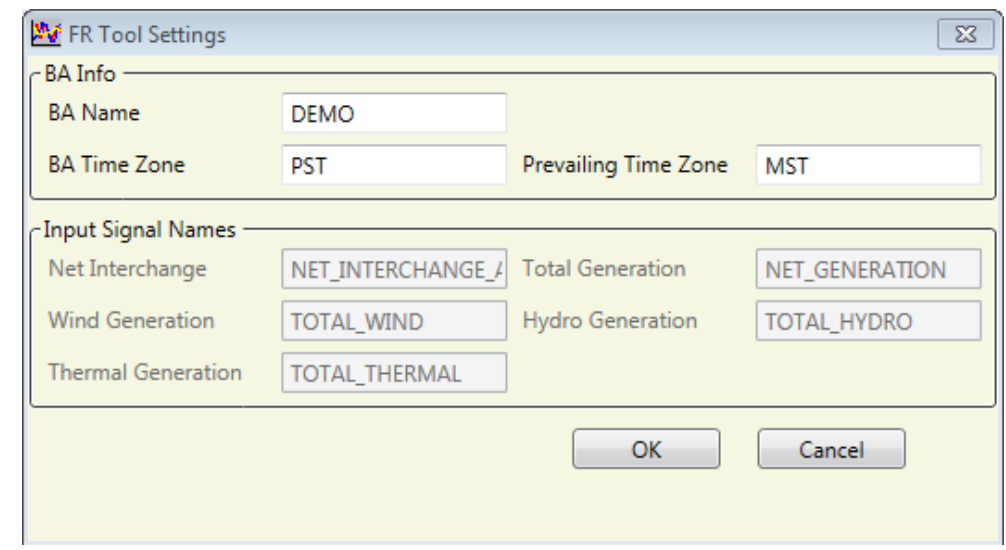

Figure 3-4. FRAT settings window.

FRAT stores this information in the program configuration file (see Figure 3-5) named "presets.xml" and can be found in "DataBase" folder. The user can manually modify the configuration xml file to change the main program setting as well as to define transmission interfaces and default measurements that should be initially selected (displayed) for a new event.

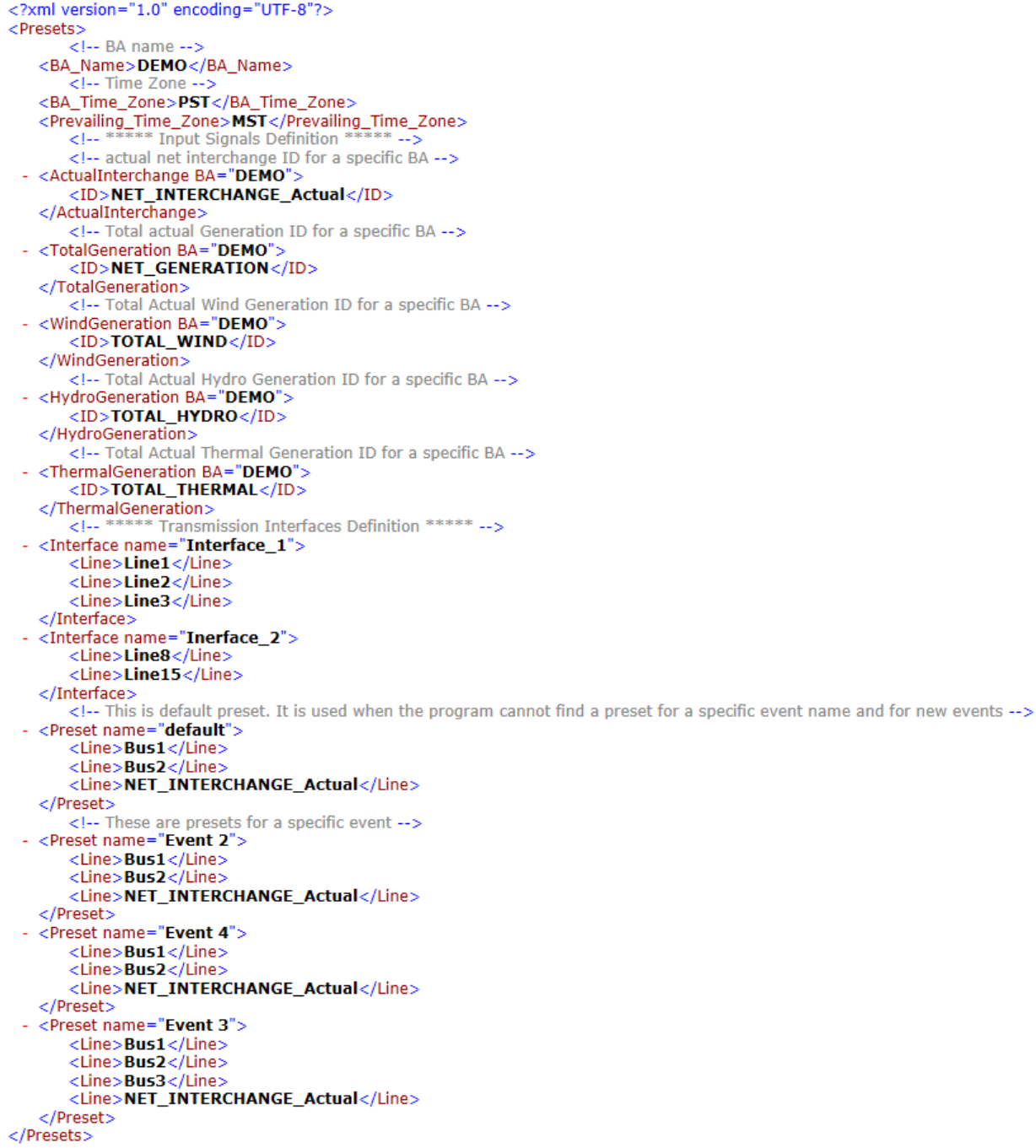

Figure 3-5. FRAT configuration file 
For example, to define a transmission interface called "XYZ", which consists from three transmission lines called "Line1", "Line2", "Line3", the following xml element should be added to the configuration file:

$$
\begin{aligned}
& \text { <Interface name="XYZ"> } \\
& \hline \text { Line }>\text { Line } 1</ \text { Line }> \\
& <\text { Line }>\text { Line } 2</ \text { Line }> \\
& \text { <Line }>\text { Line3 }</ \text { Line }> \\
& \text { </Interface }>
\end{aligned}
$$

\subsection{Input File Requirements}

The tool uses PMU and SCADA measurements as an input. The input file must be a commaseparated values (csv) format file. The FRAT can automatically recognize the type of measurement. to recognize the type of measurement, the input file format should follow WECC Guideline for Data Format Used in Engineering Analysis Applications [9]. The one row and four rows header .csv files are supported by the FRAT. The first column of the .csv file should be the time stamp. The one row header requirements are given in Table 3-1. One row header includes signal name and signal type separated by the comma. An example of one row input file is shown in Figure 3-6.

Table 3-1. One row header requirements

\begin{tabular}{|l|l|l|}
\hline$\#$ & Signal Type & Signal name \\
\hline 1 & Frequency & $* * * . F$ \\
\hline 2 & Voltage & $* * * . V$ or $* * * . V P M$ \\
\hline 3 & Active power & $* * * . P$ \\
\hline 4 & Reactive Power & $* * * . Q$ \\
\hline 5 & Angle & $* * * . A$ or $* * * . V P A$ \\
\hline \multirow{2}{*}{ where “***" should be replaced with a signal name }
\end{tabular}

a)

Time, Bus1.V,Bus1. A, Bus1.F, Line1. P, Line1.Q, Line2. P, Line2.Q, Bus2.V, Bus2. A, Bus2.F $0,543.42,-106.87,60,729.27,43.113,745.73,29.837,548.35,-160.66,59.998$

\begin{tabular}{|c|c|c|c|c|c|c|c|c|c|c|c|}
\hline 4 & A & B & C & D & $E$ & $\mathrm{~F}$ & G & H & I & J & K \\
\hline 1 & Time & Bus1.V & Bus1.A & Bus1.F & Line1.P & Line1.Q & Line2.P & Line2.Q & Bus2.V & Bus2.A & Bus2.F \\
\hline 2 & 0 & 543.42 & -106.87 & 60 & 729.27 & 43.113 & 745.73 & 29.837 & 548.35 & -160.66 & 59.998 \\
\hline 3 & 0.033333 & 543.37 & -106.88 & 60 & 729.48 & 43.298 & 746.16 & 30.161 & 548.34 & -160.69 & 59.997 \\
\hline 4 & 0.066667 & 543.33 & -106.89 & 59.998 & 729.94 & 43.566 & 746.17 & 30.152 & 548.36 & -160.71 & 59.998 \\
\hline 5 & 0.1 & 543.29 & -106.91 & 59.998 & 730.32 & 43.673 & 746.12 & 29.9 & 548.35 & -160.75 & 59.997 \\
\hline
\end{tabular}

$0.033333,543.37,-106.88,60,729.48,43.298,746.16,30.161,548.34,-160.69,59.997$

$0.066667,543.33,-106.89,59.998,729.94,43.566,746.17,30.152,548.36,-160.71,59.998$

$0.1,543.29,-106.91,59.998,730.32,43.673,746.12,29.9,548.35,-160.75,59.997$

b)

Figure 3-6. One row .csv file example: a) opened in text editor; b) opened in Excel.

The four rows header file according to the Western Electric Coordinating Council [9] should have the following structure:

Line 1 - signal names

Line 2 - signal type

Line 3 - units

Line 4 - description. 
An example of a four rows input file is shown in Figure 3-7.

a)

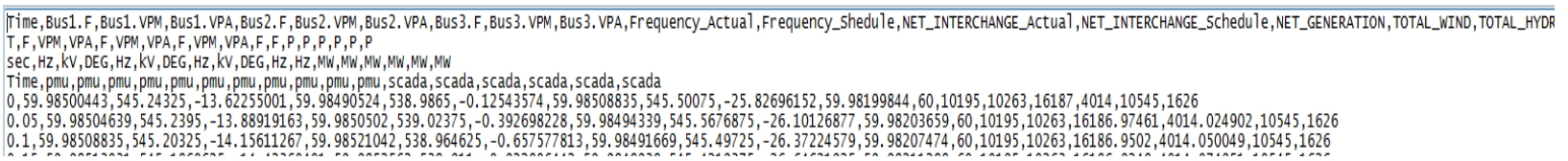

b)

\begin{tabular}{|c|c|c|c|c|c|c|c|c|c|c|c|c|c|c|c|c|c|c|c|}
\hline & A & B & C & D & E & $\mathrm{F}$ & G & H & I & $J$ & K & L & $M$ & $\mathrm{~N}$ & 0 & $p$ & Q & R & $s$ \\
\hline 1 & Time & Bus1.F & Bus1.vPM & Bus1.VPA & Bus2.F & Bus2.VPM & A Bus2.VPA & Bus3.F & Bus3.VPM & Bus3.VPA & Frequenc) & Frequenc & NET_INTE| & INET_INTE| & INET_GENE & ETOTAL_W & I TOTAL_HY & Y TOTAL_TH & MAL \\
\hline 2 & $T$ & $\mathrm{~F}$ & VPM & VPA & $\mathrm{F}$ & VPM & VPA & $\mathrm{F}$ & VPM & VPA & $\mathrm{F}$ & $\mathrm{F}$ & P & $\mathrm{p}$ & P & P & P & $\mathrm{P}$ & \\
\hline 3 & $\sec$ & $\mathrm{Hz}$ & $\mathrm{kV}$ & DEG & $\mathrm{Hz}$ & $\mathrm{kV}$ & DEG & $\mathrm{Hz}$ & $\mathrm{kV}$ & DEG & $\mathrm{Hz}$ & $\mathrm{Hz}$ & MW & MW & MW & MW & MW & MW & \\
\hline 4 & Time & pmu & pmu & pmu & pmu & pmu & pmu & pmu & pmu & pmu & pmu & pmu & scada & scada & scada & scada & scada & scada & \\
\hline 5 & 0 & 59.985 & 545.2433 & -13.6226 & 59.98491 & 538.9865 & -0.12544 & 59.98509 & 545.5008 & -25.827 & 59.982 & 60 & 10195 & 10263 & 16187 & 4014 & 10545 & 1626 & \\
\hline 6 & 0.05 & 59.98505 & 545.2395 & -13.8892 & 59.98505 & 539.0238 & -0.3927 & 59.98494 & 545.5677 & -26.1013 & 59.98204 & 60 & 10195 & 10263 & 16186.97 & 4014.025 & 10545 & 1626 & \\
\hline 7 & 0.1 & 59.98509 & 545.2033 & -14.1561 & 59.98521 & 538.9646 & -0.65758 & 59.98492 & 545.4973 & -26.3722 & 59.98207 & 60 & 10195 & 10263 & 16186.95 & 4014.05 & 10545 & 1626 & \\
\hline
\end{tabular}

Figure 3-7. Four rows .csv file example: a) opened in text editor; b) opened in Excel.

\subsection{Event Database Panel}

The events database screen is used to view the information about all frequency events available for analysis (Figure 3-8). Non-qualifying events are highlighted using gray color and they are not used for system baselining and statistical analysis. When a user selects any event from the list of event characteristics panel, the event plot panel are updated automatically to display detailed information about the selected event. The selected event is also highlighted at the baselining plot.

\begin{tabular}{|c|c|c|c|c|c|c|}
\hline \multicolumn{6}{|l|}{ Events DataBase } & \multirow{13}{*}{$\begin{array}{l}\text { Non } \\
\text { qualifying } \\
\text { event (gray) }\end{array}$} \\
\hline Event Name & Date & Time & Disturbance & FRM NERC & FRM BA & \\
\hline Event 1 & $10 / 02 / 08$ & 14:51:00 & 2000 & \begin{tabular}{|l}
1587.302 \\
\end{tabular} & 0 & \\
\hline event 2 & $09 / 27 / 10$ & 14:51:01 & 2000 & 1612.903 & 0 & \\
\hline Event 3 & $07 / 03 / 13$ & 11:00:00 & 2100 & 1680 & 0 & \\
\hline Event 4 & 05/06/07 & 0:00:00 & 2000 & 1242.236 & 0 & \\
\hline Event 5 & 05/06/09 & 5:00:00 & 2100 & \begin{tabular}{|l|}
1304.348 \\
\end{tabular} & 0 & \\
\hline Event 6 & $05 / 10 / 14$ & $0: 00: 00$ & 1506 & 1673.333 L & -216.913 & \\
\hline Event 7 & $05 / 10 / 12$ & $10: 25: 00$ & 1604 & 1865.116 & 409.552 & \\
\hline Event 8 & $01 / 15 / 13$ & $15: 00: 00$ & 1050 & 1640.625 & 504.166 & \\
\hline Event 9 & $03 / 02 / 14$ & $00: 00: 00$ & 1500 & 1304.348 & 531.81 & \\
\hline Event 10 & $07 / 02 / 14$ & 08:00:00 & 1600 & 1391.304 & $619 \div 38$ & \\
\hline Event 12 & 07/10/09 & 11:21:15 & 1305 & \begin{tabular}{|l|}
1144.737 \\
\end{tabular} & 363.338 & \\
\hline Event 13 & $11 / 05 / 11$ & 3:00:00 & 600 & \begin{tabular}{|l|}
521.739 \\
\end{tabular} & -773.606 & \multirow{2}{*}{$\begin{array}{l}\text { Selected event } \\
\text { (blue) }\end{array}$} \\
\hline Event 11 & $03 / 05 / 13$ & $22: 00: 00$ & 444 & 693.75 & 312.608 & \\
\hline
\end{tabular}

Figure 3-8. Events database screen.

The FRAT archives all information in the frequency events database. The .csv file is used to store frequency events information. The structure of the database is given in Table 3-2. 
Table 3-2. Event characteristics columns definition

\begin{tabular}{|c|c|c|}
\hline & Column Name & Definition \\
\hline \multirow{5}{*}{ Event Description } & Name & Event name \\
\hline & Date & Event date \\
\hline & Time & Event time \\
\hline & Day & Day of week \\
\hline & Qualifying event & Qualifying event (Yes or No) \\
\hline \multirow{12}{*}{$\begin{array}{l}\text { Load/ } \\
\text { Generation }\end{array}$} & Generation loss & Generation loss \\
\hline & Load loss time & Load loss time \\
\hline & Load loss & Load loss \\
\hline & Total generation & Total generation \\
\hline & Thermal generation & Thermal generation \\
\hline & Hydro generation & Hydro generation \\
\hline & Wind generation & Wind generation \\
\hline & BA generation loss & BA generation loss \\
\hline & BA generation & BA generation \\
\hline & BA thermal generation & BA thermal generation \\
\hline & BA hydro generation & BA hydro generation \\
\hline & BA wind generation & BA wind generation \\
\hline \multirow{10}{*}{$\begin{array}{l}\text { Time/ } \\
\text { Frequency }\end{array}$} & Initial time & Initial time \\
\hline & Minimum time & Minimum time \\
\hline & Settling time & Settling time \\
\hline & Initial frequency & Initial frequency \\
\hline & Minimum frequency & Minimum frequency \\
\hline & Settling frequency & Settling frequency \\
\hline & Frequency 20 & Frequency at 20 seconds \\
\hline & Frequency 30 & Frequency at 30 seconds \\
\hline & Frequency 60 & Frequency at 60 seconds \\
\hline & Frequency 90 & Frequency at 90 seconds \\
\hline \multirow{9}{*}{$\begin{array}{l}\text { NERC } \\
\text { Performance }\end{array}$} & FA NERC & Frequency at point $\mathrm{A}$ \\
\hline & FB NERC & Frequency at point $\mathrm{B}$ \\
\hline & FRM NERC & Interconnection frequency response measure $(\mathrm{MW} / 0.1 \mathrm{~Hz})$ \\
\hline & PA Interchange & Interchange at point $\mathrm{A}$ \\
\hline & PB Interchange & Interchange at point $\mathrm{B}$ \\
\hline & FRM BA & Frequency response measure of the balancing authority $(\mathrm{MW} / 0.1 \mathrm{~Hz})$ \\
\hline & PA Generation & Generation power at point $\mathrm{A}$ \\
\hline & PB Generation & Generation power at point $B$ \\
\hline & FR Gen BA & FRM calculated using balancing authority generation \\
\hline \multirow{6}{*}{$\begin{array}{l}\text { Additional } \\
\text { Performance } \\
\text { Indexes }\end{array}$} & FRM Min & Interconnection FRM at point $\mathrm{C}$ (minimum point) \\
\hline & FRM B & Interconnection FRM at point $\mathrm{B}$ \\
\hline & FRM 20 & Frequency response measurement at 20 seconds \\
\hline & FRM 30 & Frequency response measurement at 30 seconds \\
\hline & FRM 60 & Frequency response measurement at 60 seconds \\
\hline & FRM 90 & Frequency response measurement at 90 seconds \\
\hline
\end{tabular}

\subsection{Event Characteristics Panel}

Event characteristics panel displays information about a frequency event (Figure 3-9). This information is arranged in several groups. Each group can be collapsed or expanded to save the screen space using expand/collapse button ${ }^{\star}$. 


\subsubsection{Event Description Group}

The event description group includes information on event name, event date, and time. Day of the week is identified automatically based on the date of event. The user also can add some comments to the event. The event description also provides information on the status of the event (qualifying/nonqualifying) using a check box.

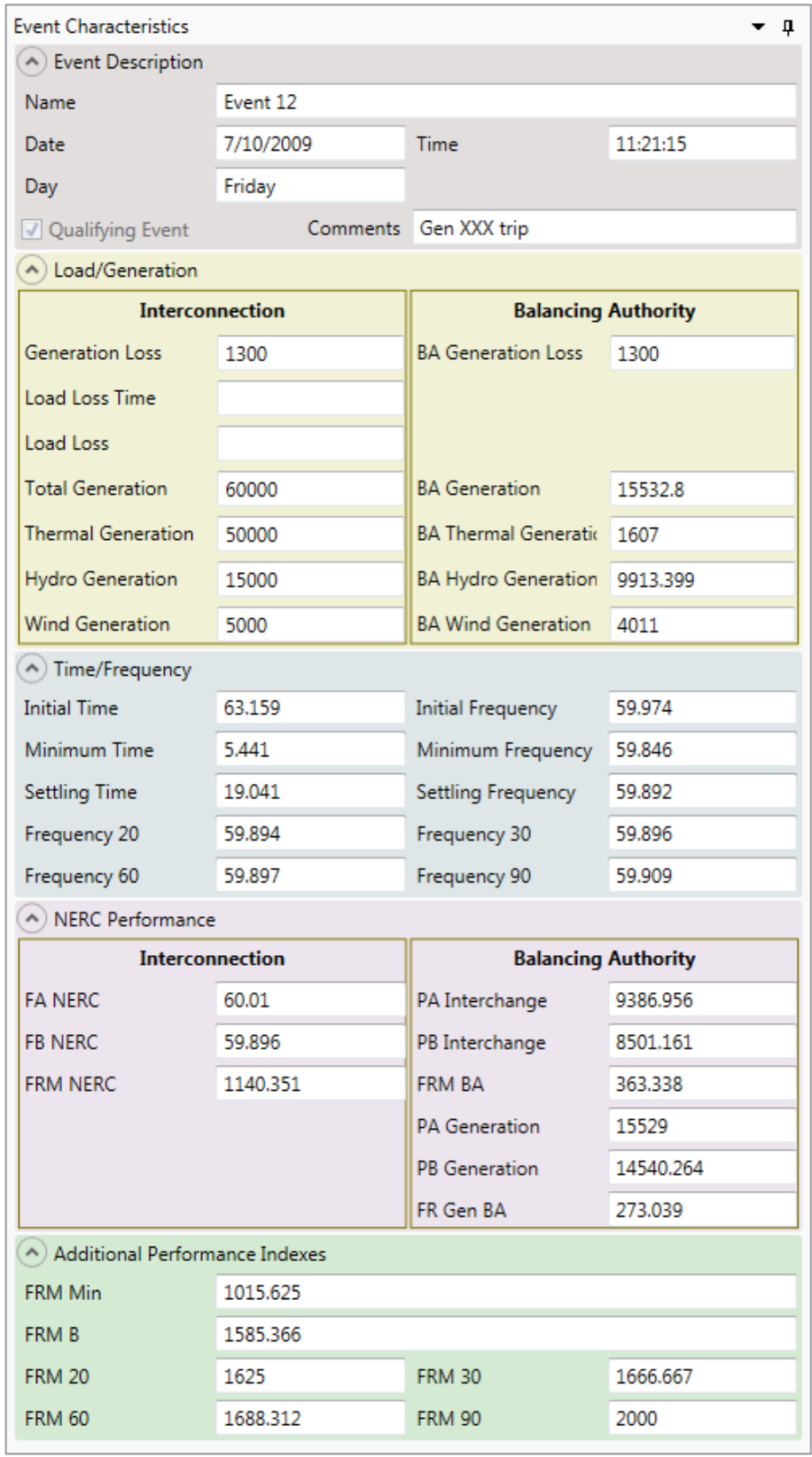

Figure 3-9. Event characteristics screen 


\subsubsection{Load/Generation Group}

Load/generation group includes information on interconnection and BA generation/load including:

- Generation loss

- Load loss size and time

- Total generation

- Thermal generation

- Hydro generation

- Wind generation.

\subsubsection{Time/Frequency Group}

Time/frequency group includes information on the interconnection frequency including:

- Initial time and frequency

- Minimum time and frequency

- Settling time and frequency

- Frequency at time $\mathrm{t}_{0}+20, \mathrm{t}_{0}+30, \mathrm{t}_{0}+60$, and $\mathrm{t}_{0}+90$.

\subsubsection{NERC Performance Group}

The NERC performance group includes information on interconnection frequency values, BA interchange values, and interconnection/BA FRM indexes:

- Point A frequency

- Point B frequency

- Point A interchange value

- Point B interchange value

- Interconnection FRM

- BA FRM

- Point A BA generation

- Point B BA generation

- BA FRM based on generation.

These three parameters are not part of the NERC BAL-003-01 Standard

\subsubsection{Additional Performance Indexes Group}

Additional performance indexes group includes information on additional interconnection indexes calculated by FRAT including:

- FRM at minimum point

- FRM at settling point

- FRM at time $\mathrm{t}_{0}+20, \mathrm{t}_{0}+30, \mathrm{t}_{0}+60$, and $\mathrm{t}_{0}+90$.

\subsection{Event Plot Panel}

The event plot panel displays the event graph (Figure 3-10). It consists from several subplots to display frequency, active power and voltage graphs. Additional panels with graph settings can be 
collapsed or expanded on the left side of the screen using expand/collapse button ${ }^{(3)}$. Graph settings include a set of checkboxes to:

- Turn on and off frequency, active power and voltage subplots

- Turn on and off performance points

- NERC points A and B (red horizontal dashed lines)

- Initial point $\left(\mathrm{F}_{0}\right)$

- Minimum point $\left(\mathrm{F}_{\mathrm{min}}\right)$

- Settling point $\left(\mathrm{F}_{\text {settling }}\right)$

- Frequency at time $\mathrm{t}_{0}+20, \mathrm{t}_{0}+30, \mathrm{t}_{0}+60$, and $\mathrm{t}_{0}+90$

- Turn on and off the legend

- To select PMU and SCADA measurements to be displayed

- To turn on and off the mean frequency curve calculated based on the selected frequency signals.

The user can pan and zoom the plot as well as copy it to clipboard. The plot can be controlled using the following actions:

- Mouse wheel - to zoom the plot

- Mouse wheel over an axis - to zoom only selected axis

- Hold left mouse button and move the mouse to pan the plot

- Press "A" button to reset the plot to initial (auto) ranges

- Press Ctrl+C to copy the plot to clipboard

- Hold Ctrl + right mouse button - to select an area to display
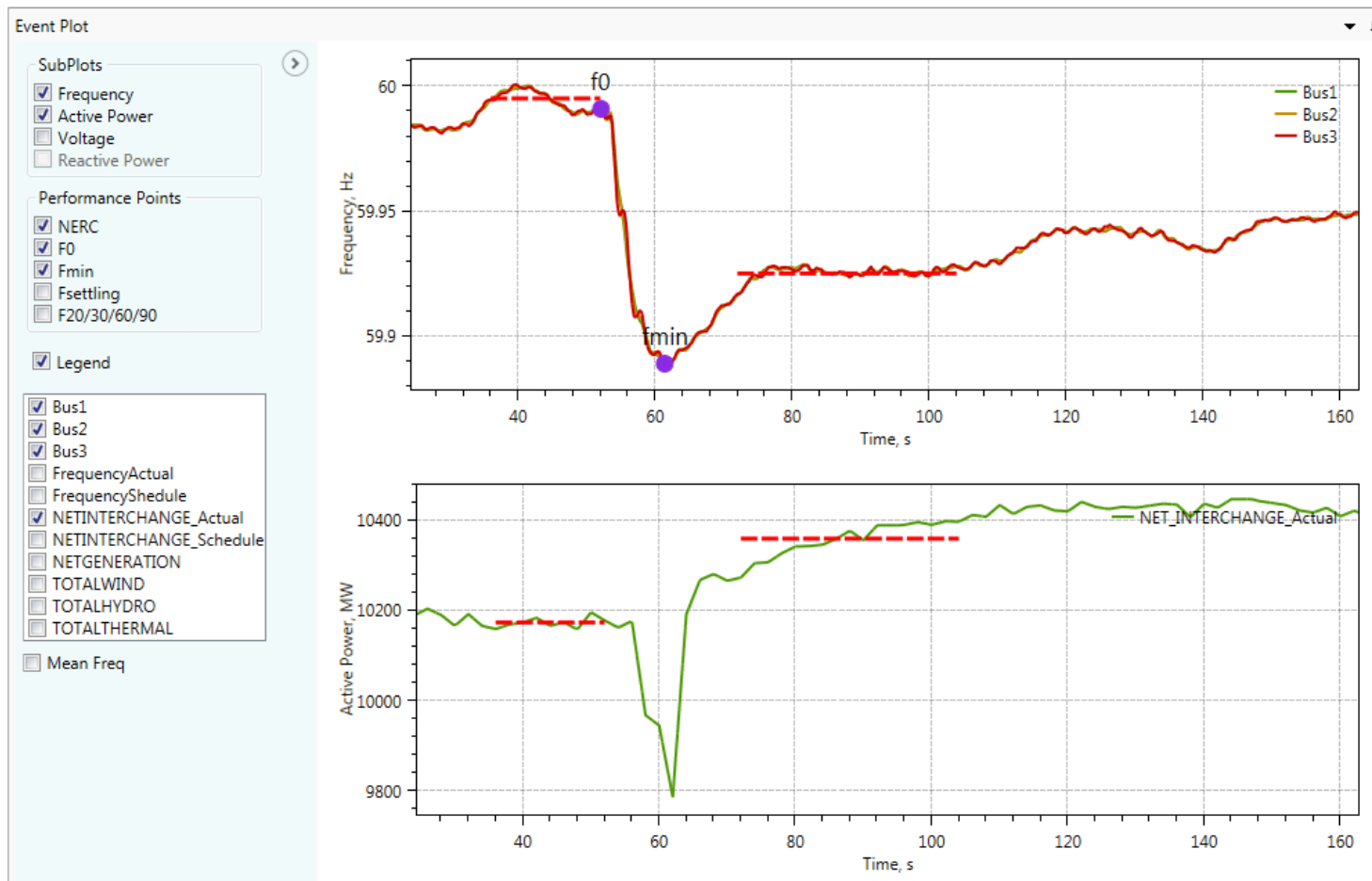

Figure 3-10. Event plot screen. 


\subsection{FRM Baseline and Statistical Analysis Screen}

The baselining panel displays the FRM baseline plot for interconnection and BA (Figure 3-11). The screen consists from two tabs. The first tab is for interconnection analysis and the second tab is for BA analysis. On the right side of the screen, it also includes the statistical analysis panel that can be collapsed or expanded using expand/collapse button $\odot$. The plot settings panel is located on the left side of the screen and it can be also expanded.

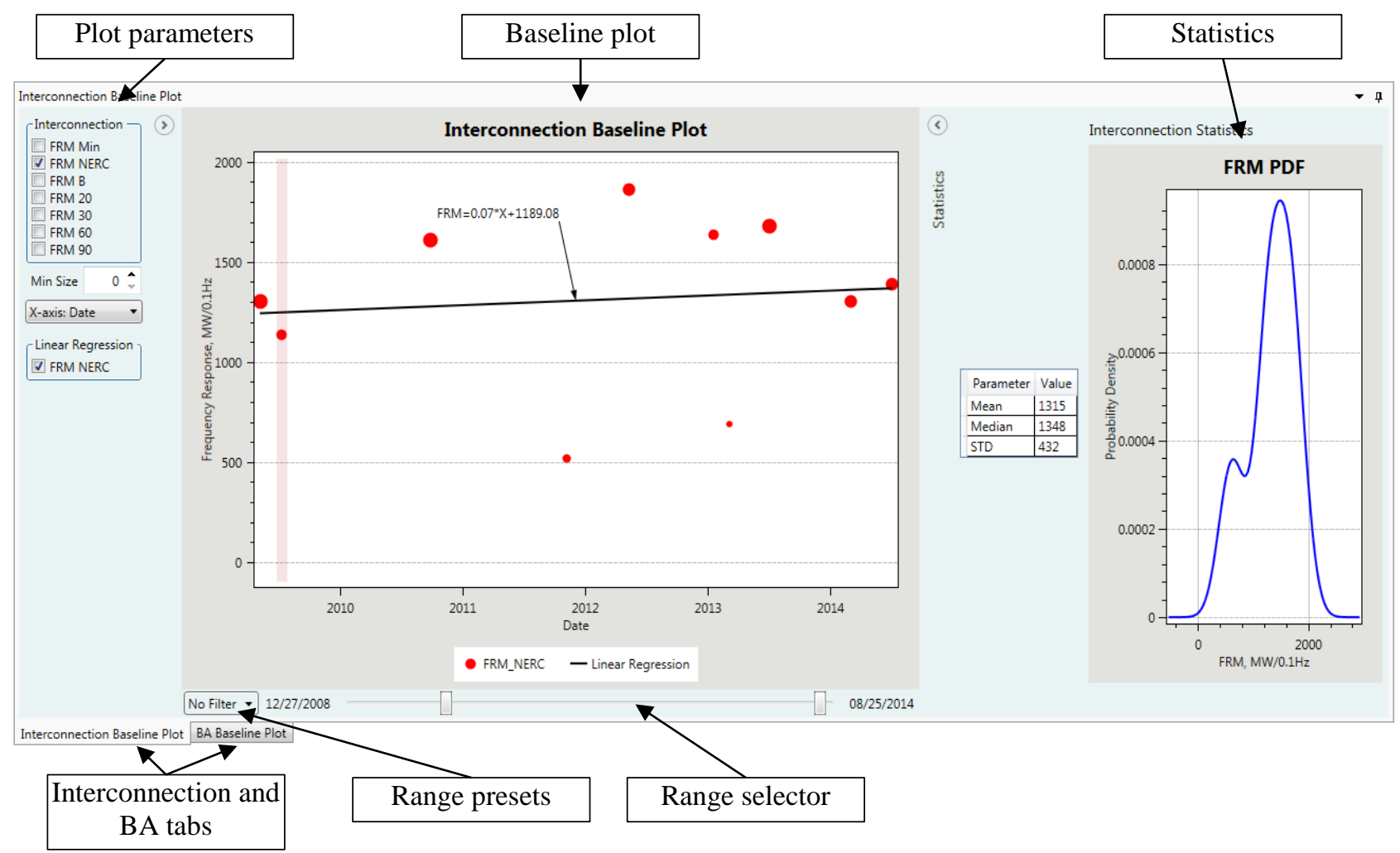

Figure 3-11. Baseline plot screen

\subsubsection{Baseline Plot}

Based on the statistical information collected in the database, the FRAT is capable of generating different type of plots illustrating system frequency response characteristics. The baselining plot shown in Figure 3-11 illustrates changing of interconnection FRM (MW/0.1 Hz) from the selected time range. The size of points in the baselining plot depends on the size of the disturbance. The different types of plot are also available. For example, the FRAT can correlate FRM metrics with the size of event or with generation mix (hydro, thermal, wind and solar generation).

The user can select any dots on the baseline plot to get information about this event. The information and graphs at the event characteristics and event plot panels are updated automatically when a user clicks on the event at the baseline plot. 
At the bottom of the baseline plot there is a range selector to select the studied range (see Figure 3-12). There is also a drop-box list with range. For example, only the current year or 1 year window can be selected.

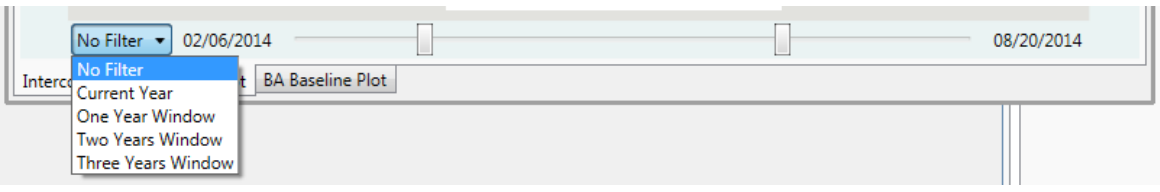

Figure 3-12. Baseline plot range selector

Baseline plot settings panel includes the following elements:

- Check boxes to select performance metrics to display (FRM at minimum point, FRM at point B, FRM at settling point, FRM at time t0+20, etc.)

- Plot X-axis type (date, time, disturbance size, generation mix, etc.)

- Turn on/off linear regression curve.

\subsubsection{FRM Statistical Analysis}

The statistical analysis screen includes FRM probability density function (PDF) plot and information of the FRM statistical parameters (mean value, median value and Standard deviation) for the selected range (Figure 3-13).

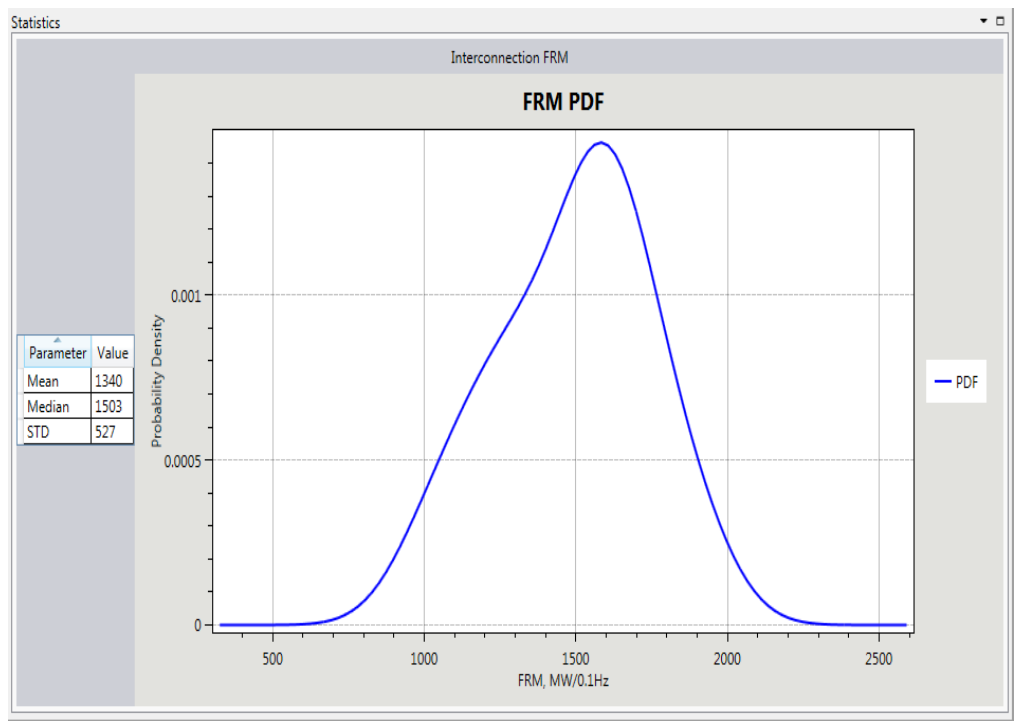

Figure 3-13. Statistical analysis of the interconnection FRM

The FRAT also performs linear regression analysis to estimate the FRM time trend. A linear regression equation is a statistical model to describe the relationship between time and FRM. The equation can be expressed as follows:

$$
F R M=A * T i m e+B
$$


where FRM is the frequency response measurement value $(\mathrm{MW} / 0.1 \mathrm{~Hz})$.

Time variable represents a time that could be years, months, days, hours, minutes and seconds. $A$ is the slope of the regression line and $B$ is the intercept of the regression line.

To calculate parameter $A$ and $B$, the error between the regression line and the real data should be minimized.

$$
\min \sum_{i=1}^{N}\left(y_{i}-\tilde{y}_{i}\right)
$$

where $y_{i}$ is the $i^{\text {th }}$ FRM data and $\tilde{y}_{i}=A x_{i}+B, x_{i}$ is the $i^{\text {th }}$ time data and $N$ is the total number of data.

The linear regression problem is solved using a least squares method. Details on this method can be found in NERC Frequency Response Initiative Report [3] and Weinstein[10].

\subsection{Editing Event Database}

To edit an event in the database, the user should select this event in the "events database" screen and then click the "edit" button . After the FRAT switched to the "edit" mode, the background of the frequency plot is changed to yellow color (Figure 3-14). In edit mode, the user can manually adjust the values of the initial, minimum, and other points. To manually adjust the location (value) of the point, select it using the mouse. Then, to move the selected point, press and hold the left mouse button. Drag the point to a new location. When the initial point is adjusted, the values of $t 0+20, t 0+30, t 0+60$, and $t 0+90$ points are updated automatically. The FRAT also recalculates FRM values every time the FR performance points are modified. 


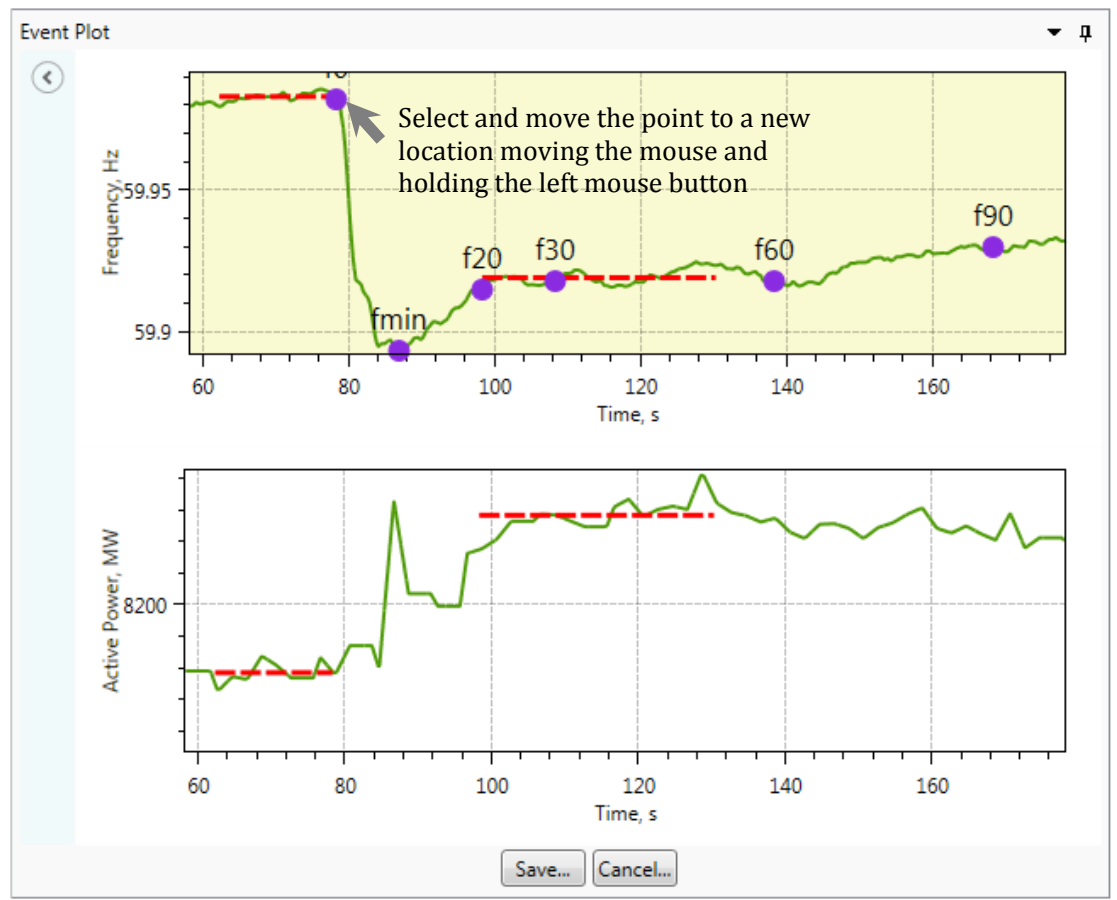

Figure 3-14. Event plot in "edit" mode.

In edit mode, the user also can change the values generation/load loss, generation production, and other parameters at the event characteristics screen. The name of event can be also changed. To save the modified information in the database, the "save" button should be pressed.

To delete an event, select this event and then click the "delete" button $\mathbf{X}$.

\subsection{Adding New Event}

To add a new event, click the "add event" button The user will be asked to select the input file with the SCADA and/or PMU information. Input file requirements are given in Section 3.4.

The FRAT provides the initial estimates of the following parameters:

1. Initial point: $\mathrm{f}_{0}$ - pre-fault frequency;

2. Point A frequency (average frequency at interval $t_{0-16}$ to $t_{0}$ )

3. Minimum point: $\mathrm{f}_{\min }-$ minimum frequency value (frequency nadir);

4. Settling point: $f_{\text {settle }}-$ settling frequency value;

5. Point B frequency (average frequency at interval $t_{0+20}$ to $t_{0+52}$ )

6. Frequency at time $\mathrm{t}_{0}+20 \mathrm{~s}: \mathrm{f}_{20}$;

7. Frequency at time $\mathrm{t}_{0}+30 \mathrm{~s}: \mathrm{f}_{30}$;

8. Frequency at time $\mathrm{t}_{0}+60 \mathrm{~s}: \mathrm{f}_{60}$;

9. Frequency at time $t_{0}+90 \mathrm{~s}: \mathrm{f}_{60}$; 
At the next step, the user can visually inspect the results of estimation and adjust estimated points if it is necessary. The points' adjustment procedure is similar to the editing process explained in the previous section (Section 3.9).

The user also should provide the size of event (generation loss), specify the date and time of event, and enter the name of event.

After the user confirms that parameters estimation is correct and enters the size of disturbance, the tool calculates frequency response performance characteristics:

1) FRM at point B according to the NERC BAL-003-01 Standard

2) FRM at minimum point, $\mathrm{MW} / 0.1 \mathrm{~Hz}$

3) FRM at settling point, $\mathrm{MW} / 0.1 \mathrm{~Hz}$

4) FRM at time $20 \mathrm{sec}, \mathrm{MW} / 0.1 \mathrm{~Hz}$

5) FRM at time $30 \mathrm{sec}, \mathrm{MW} / 0.1 \mathrm{~Hz}$

6) FRM at time $60 \mathrm{sec}, \mathrm{MW} / 0.1 \mathrm{~Hz}$

7) FRM at time $90 \mathrm{sec}, \mathrm{MW} / 0.1 \mathrm{~Hz}$.

The FRM metrics are calculated for the interconnection and for the BA. To save the new event in the database, the "save" button should be clicked. After the new event is entered to the database, the baseline plot is updated automatically.

\subsection{FRAT Report Generation}

To open the report window, the "show report" button should be clicked. The report screen is shown in Figure 3-15. To generate the report, the "FR report" button should be pressed. To include event plots in the report, the "add event plot" checkbox can be selected. Figure 3-15 shows an example of the report automatically generated be FRAT. The generated report can be copied to the clipboard or saved to the file in MS Word format by pressing the button "save" 圆 button.

To generate FRS 1 form, the "NERC FRS1"button can be pressed. An example of FRS 1 form report is given in Figure 3-16. 


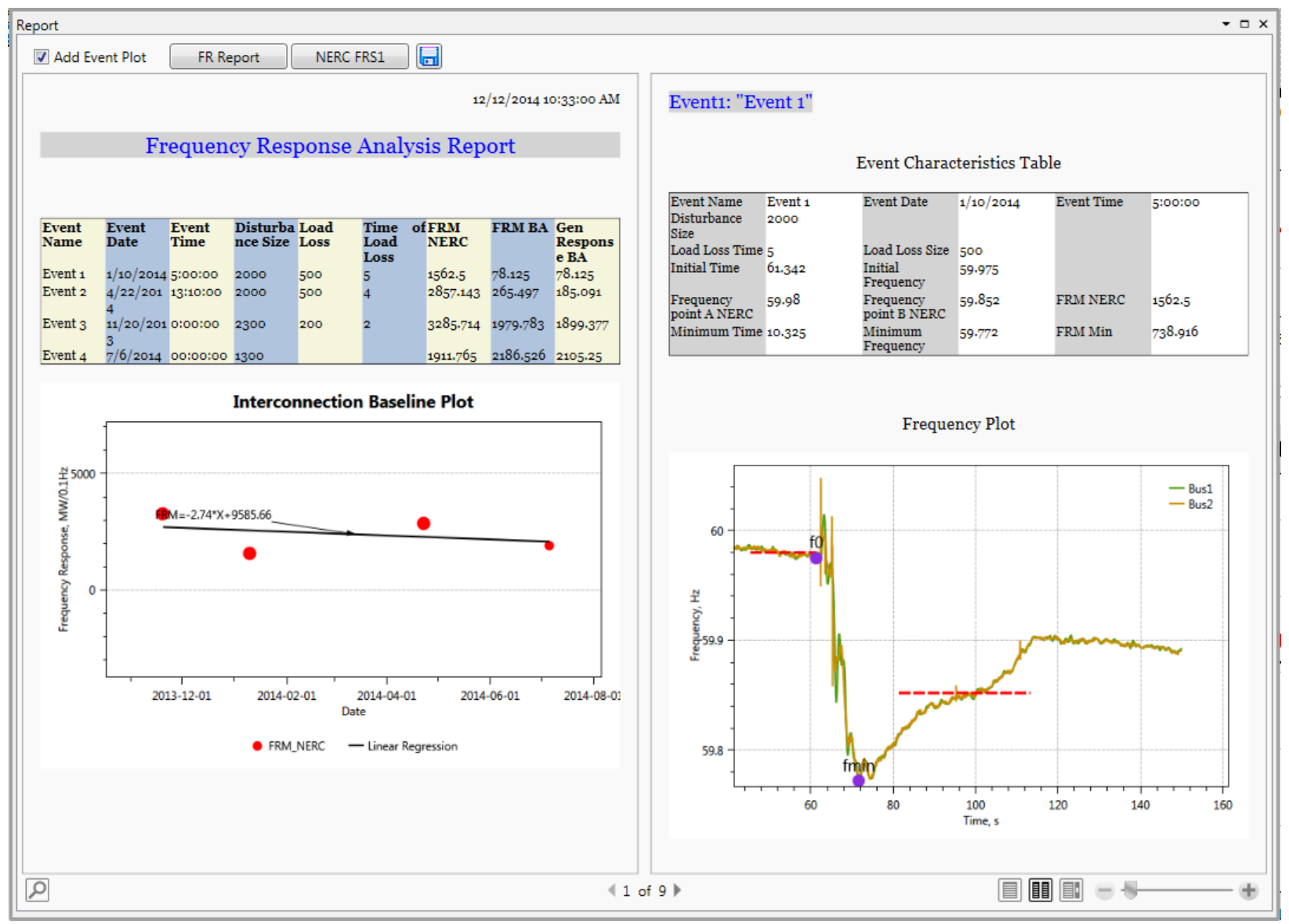

Figure 3-15. Frequency response analysis report screen

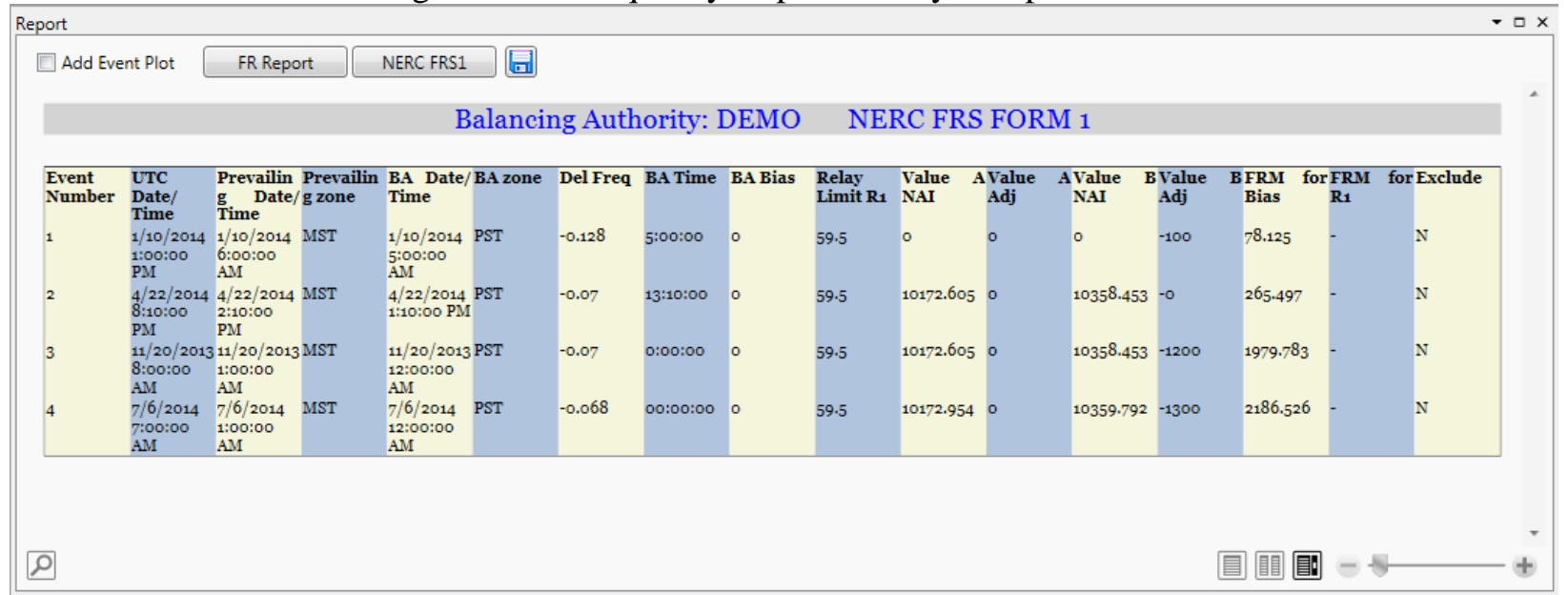

Figure 3-16. FRS 1 form.

\subsection{FRAT Requirement}

Operating system: Windows XP or higher.

Prerequisites: Microsoft .Net 4.0 Framework 
Hardware requirements: should meet Microsoft .NET 4.0 system requirements

\subsection{Program Repository}

The FRAT repository is: https://svn.pnl.gov/FRTool

The repository is based on Trac technology. Trac is a web-based software project management and bug/issue tracking system. It also provides an integrated Wiki, an interface to version control systems (Figure 3-17).

Registered users can get access to the latest version of the tool, contribute to the program source code, manuals (using integrated Wiki) as well as create new tickets (in case of bugs/issues detected). Program documentation is also available (Figure 3-18); it is automatically generated using a Doxygen document generator ${ }^{1}$.

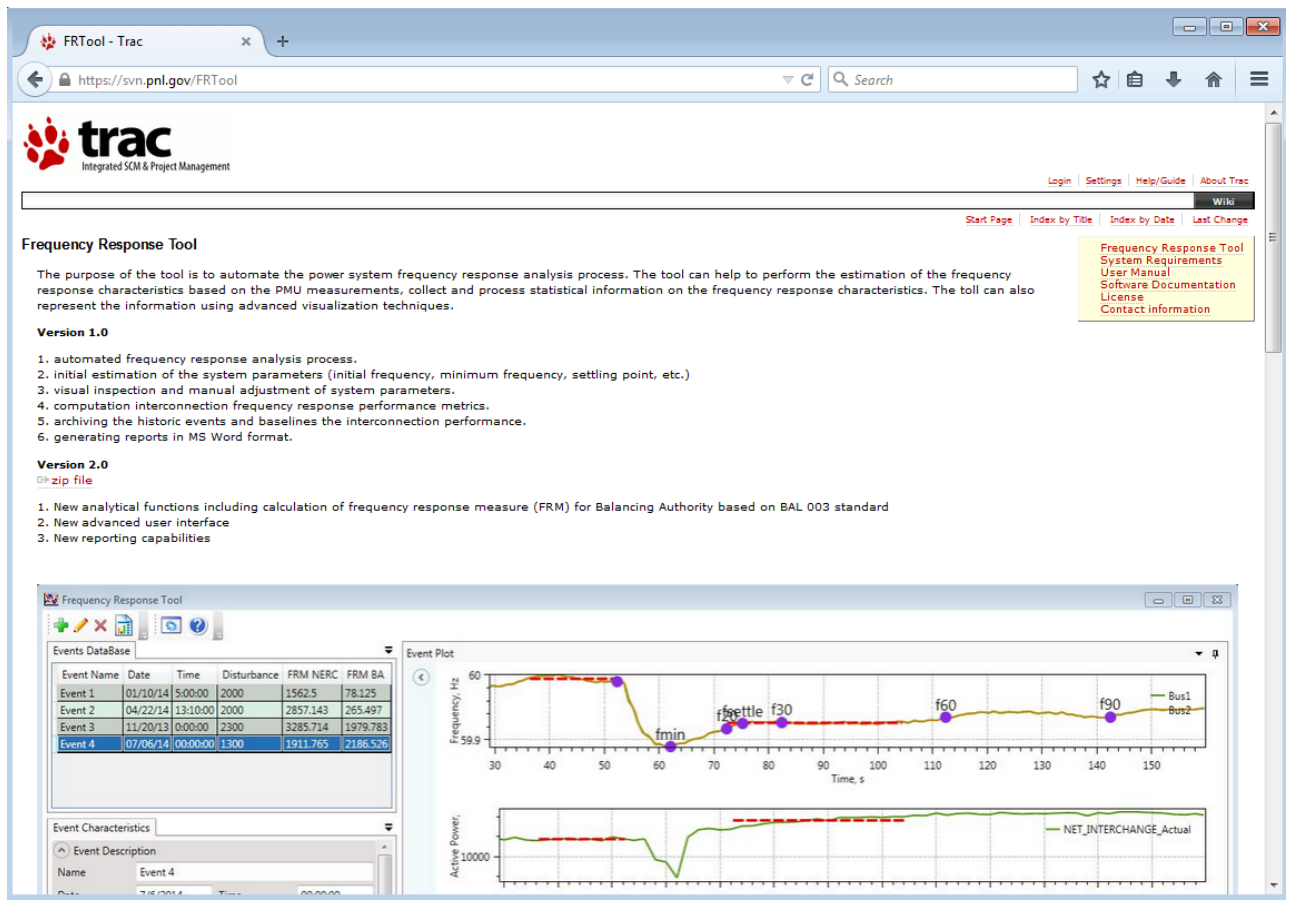

Figure 3-17. FRAT repository (main Wiki page)

\footnotetext{
${ }^{1}$ http://www.stack.nl/ dimitri/doxygen/index.html
} 


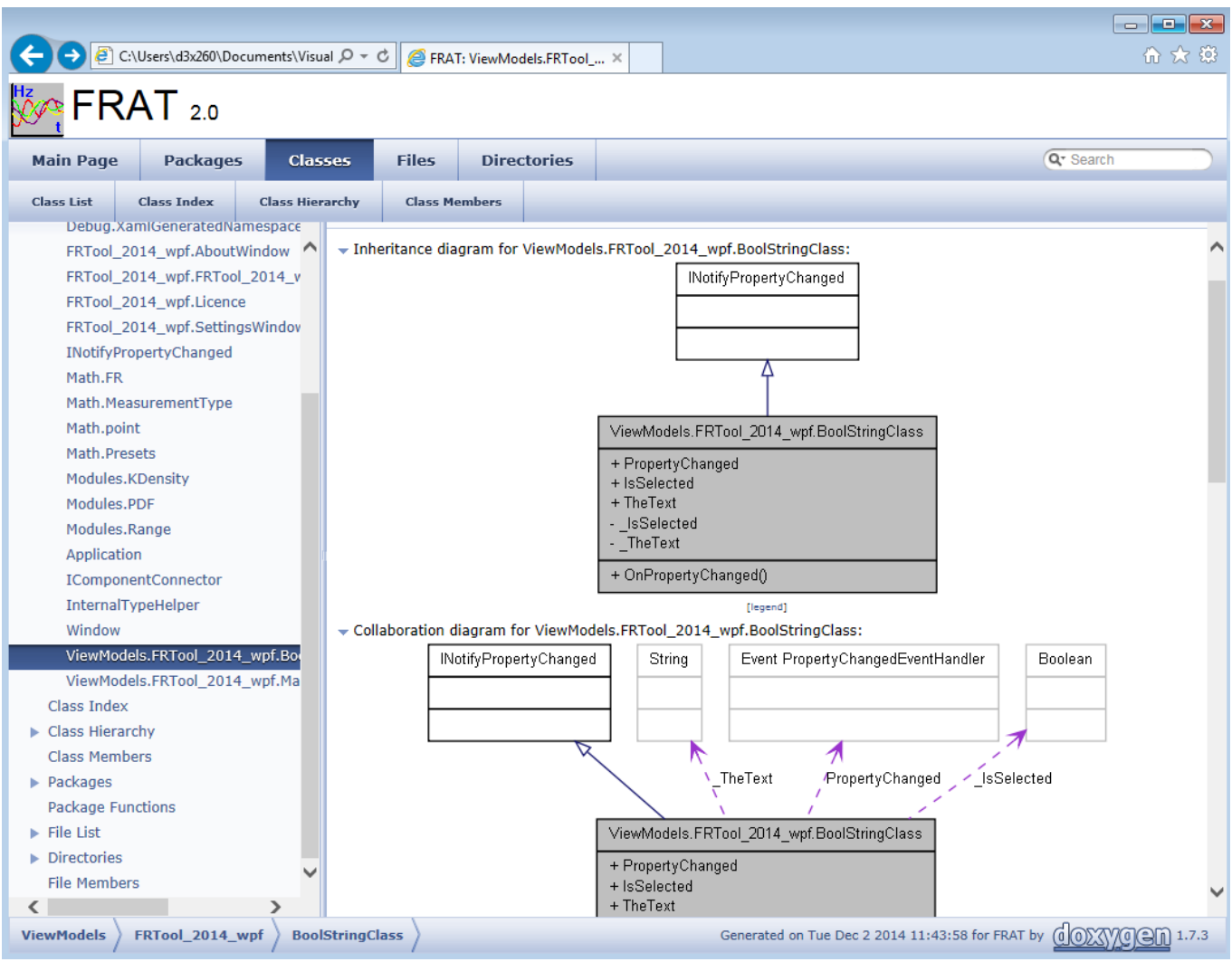

Figure 3-18. FRAT documentation 


\subsection{FR of the Western Interconnection}

With the database of frequency events developed, a variety of plots can be made for frequency response analysis [8]. Figure 4-1 shows a baseline of frequency response in the Western Interconnection. Red dots represent frequency response measure calculated using the NERC FRM methodology. Blue diamonds represent frequency response measure at nadir frequency. The size of the dots is proportional to amount of generation lost during an event. A few observations on the WECC frequency response baseline can be made:

- The interconnection response is very consistent over the years, particularly for large events,

- Western Interconnection performance averages about 1,400 to $1,600 \mathrm{MW}$ per $0.1 \mathrm{~Hz}$, which is well above NERC Western interconnection frequency response obligation of about 950 MW per $0.1 \mathrm{~Hz}$

- Nadir response, as discussed earlier, is a more consistent measure of the frequency response

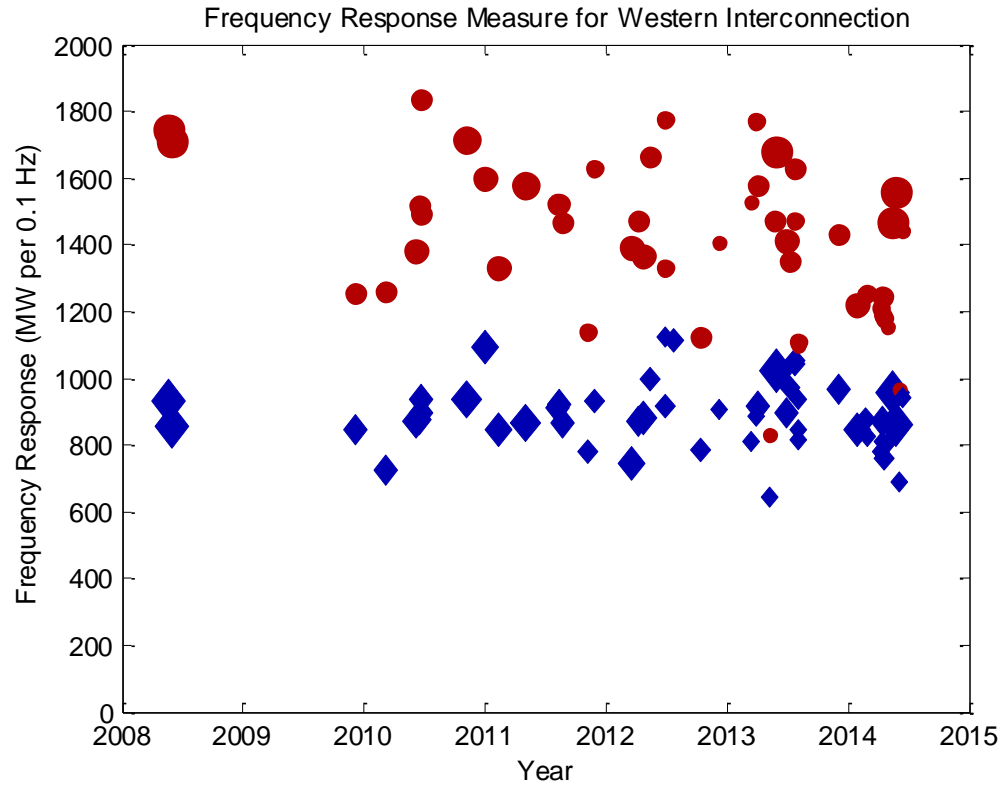

Figure 4-1. Frequency response baseline for Western Interconnection.

Figure 4-2 shows a relationship between the frequency response metrics and size of the disturbance event. Red dots represent NERC FRM calculations at the settling frequency, and blue diamonds represent the response at the frequency nadir. The size of a dot is proportional to date of event, so large dots are more recent events. NERC FRM is consistent for larger events, while there is wide variability in measured frequency response for smaller events. Frequency response at the nadir appears to be more consistent over a wide range of events. 


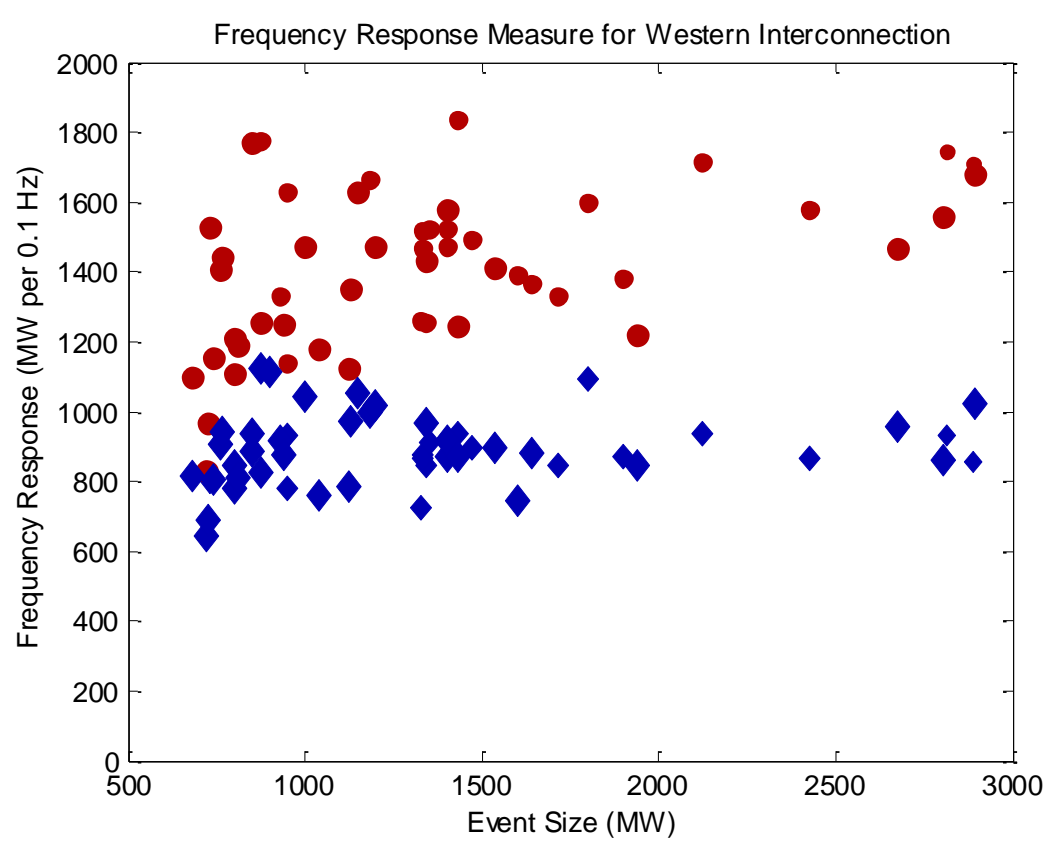

Figure 4-2. Relationship between event size and historic frequency response measure

Figure 4-3 shows a relationship between frequency deviations at nadir (C) and settling (B) points. The ratio appears to increase with larger events, as expected from the system physics.

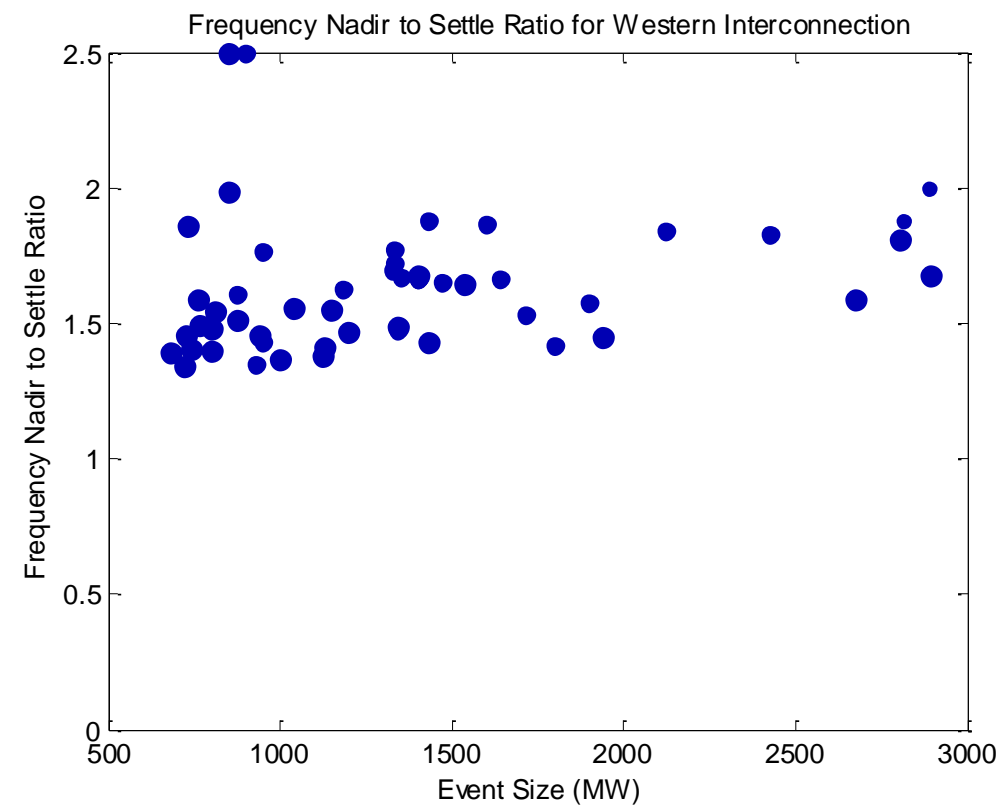

Figure 4-3. Ratio between frequency deviations at nadir (C) and settling (B) points 


\subsection{Conclusions}

- Frequency response is a measure of an interconnection's ability to stabilize frequency immediately following the sudden loss of generation or load. Recently, NERC developed the Frequency Response BAL-003-1 Standard. The Standard was approved by FERC with an effective date April 1, 2015.

- PNNL, in cooperation with BPA and WECC JSIS, developed a tool to automate the analysis of interconnection/balancing authority frequency response. The PNNL FRAT 2.0 application was released under an open source license in August 2014. The FRAT is a standalone Windows application developed in VB.NET using Microsoft Visual Studio 2012. The tool is based on the WPF technology and has advanced visualization capabilities and a user friendly GUI.

- The FR analysis tool calculates NERC frequency response measure (FRM) using PMU and/or SCADA measurements according to BAL-003-01 Standard. The tool also archives the historic events, baselines the system performance and automatically generates reports.

- The developed PNNL FRAT application has been used by interconnections and balancing authorities for a FR performance analysis and baselining.

- The FRAT application was presented at industrial events including:

- NERC Frequency Working Group

- NERC Resources Subcommittee

- ERCOT Phasor Measurement Task Force

- WECC JSIS

- WECC Modeling and Validation Work Group (MVWG)

- Webinars for ISO New England and ERCOT.

- The tool received very positive feedback from the industry. Multiple entities expressed their interest to start testing and using the tool (including ISO New England, ERCOT, and NERC Frequency Working Group). The industrial users also provided valuable feedback for the continuing research. Based on the industry feedback, the major improvement of the tool should be extending the tool functionality to perform FR analysis of the individual generation units.

- The FRAT industry outreach will include:

- Working closely with NERC (primarily with NERC Resources Subcommittee and Frequency Working Group) to promote nationwide dissemination of the tool among BAs and other electrical utilities.

- Working closely with NERC and CERTS to establish continuing support and maintenance of the FRAT.

- Working with BPA, ISO New England, ERCOT, WECC, and other BAs and utilities to provide them FR tool support and also to receive their feedback.

- Making presentations at NASPI, WECC JSIS, WECC MVWG, IEEE and other industrial meetings and workshops.

- The FRAT repository and online documentation can be found at: https://svn.pnl.gov/FRTool 


\subsection{References}

[1] Federal Energy Regulatory Commission, Docket RM13-11, Frequency Response and Frequency Bias Setting Reliability Standard, 144 FERC II 61,057 (July 18, 2013) (NOPR).

[2] North American Electric Reliability Corporation. 2014. "NERC BAL-003-1 Frequency Response and Frequency Bias Setting Reliability Standard", Atlanta, GA.

[3] North American Electric Reliability Corporation, "NERC Frequency Response Initiative Report" (2012), Atlanta, GA. October 2012, Available:

http://www.nerc.com/docs/pc/FRI\%20Report\%209-16-12\%20Draft.pdf.

[4] Eto J. et al. 2010. "Use of Frequency Response Metrics to Assess the Planning and Operating Requirements for Reliable Integration of Variable Renewable Generation.” LBNL-4142E, Lawrence Berkeley National Laboratory, Berkeley, CA. Available: http://www.ferc.gov/industries/electric/indus-act/reliability/frequencyresponsemetrics-report.pdf.

[5] Western Electricity Coordinating Council. 2004. "WECC White Paper on Frequency Response Standard", Salt Lake City, UT. Available: http://www.wecc.biz/Standards/Development/wecc0044/Shared\%20Documents/Posted\%20for\%2 0OC\%20Approval/FRR\%20White\%20Paper\%20v12_Tables_8-9.doc).

[6] Federal Energy Regulatory Commission, Docket AD13-8. 2013. "Market Implications of Frequency Response and Frequency Bias Setting Requirements" (144 FERC 1 61,058, July 18, 2013).

[7] Kosterev D. 2004. "Hydro-Turbine Model Validation in Pacific Northwest." IEEE Transactions on Power Systems, vol.19, no. 2, May 2004, pages 1144-1149.

[8] Kosterev D., D. Davies, P. Etingov, A. Silverstein, and J. Eto. 2014. "Using Synchrophasors for Frequency Response Analysis in Western Interconnection." CIGRE Grid of the Future Symposium, Houston, TX, USA, October 19 - 21, 2014.

[9] Western Electricity Coordinating Council. 2013. "WECC Guideline for Data Format Used in Engineering Analysis Applications of Disturbance and Simulated Data.", Salt Lake City UT, August 2013. Available: https://www.naspi.org/File.aspx?fileID=1210

[10] Weinstein E.W., "Least Squares Fitting.", MathWorld - A Wolfram Web Resource. Available: http://mathworld.wolfram.com/LeastSquaresFitting.html 



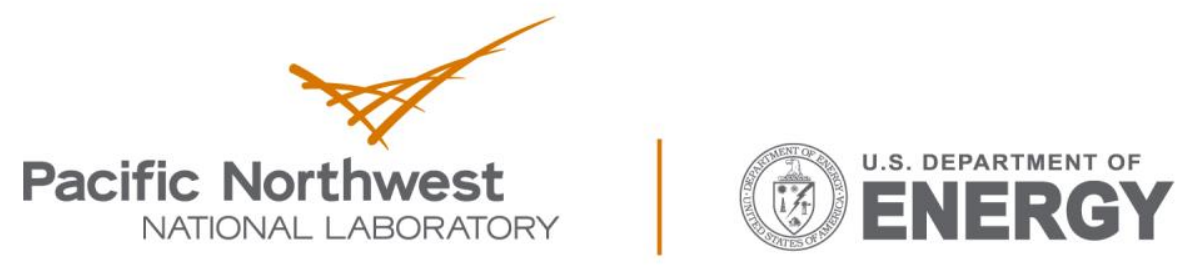

Proudly Operated by Battelle Since 1965

902 Battelle Boulevard

P.O. Box 999

Richland, WA 99352

1-888-375-PNNL (7665)

www.pnnl.gov 